\title{
THE SPECTRA OF WOLF-RAYET STARS AND RELATED OBJECTS*
}

\author{
P. SwINGs
}

\section{ABSTRACT}

New observational data are given for the spectra of several Wolf-Rayet stars. Evidence is produced for the presence of $C$ IV in the WN sequence and for a central reversal of the $H, H e \mathrm{I}$, and $H e$ II lines. The spectra of two Of stars are described, and some properties of the Of shells are discussed, especially the ionization conditions and the excitation process. The absence of well-marked dilution effects and other considerations suggest that the size of a Wolf-Rayet shell is not much larger than that of the photospheric surface, so that an occultation effect should be expected in certain cases. The relative abundances of carbon and nitrogen in the ejected shells of Wolf-Rayet, Of, and P Cygni stars, as well as of novae, are discussed, since $\mathrm{W}$ objects have been observed which are intermediate between the pure nitrogen and carbon sequences. Suggestions are made concerning the classification, absolute magnitudes, temperatures, and radii of Wolf-Rayet stars and planetary nuclei, as well as concerning the application of Zanstra's theory to the nebulae with a Wolf-Rayet nucleus or to the Wolf-Rayet stars themselves.

In the last twelve years considerable progress has been made in the interpretation of the spectra of the Wolf-Rayet stars, especially through the work of Beals. ${ }^{\mathrm{I}}$ The subdivision into nitrogen and carbon sequences, which originated mainly in the papers by Perrine, ${ }^{2}$ Lunt, ${ }^{3}$ and J. S. Plaskett, ${ }^{4}$ was discussed in considerable detail by Beals on the basis of the laboratory work by Edlén 5 and gave rise to the classification officially adopted by the International Astronomical Union at the I938 meeting (notations WN and WC). ${ }^{6}$ Simultaneous work by C. H. Payne dealt with the same subject. ${ }^{7}$ Recent papers by O. C. Wilson ${ }^{8}$ and by S. Gaposchkin ${ }^{9}$ on the eclipsing binary $\mathrm{BD}+38^{\circ} 4$ о 10 (HD I93576, HV IIIII; $\mathrm{WN}_{5}+\mathrm{Br}$ ) have also thrown some new light on the physical characteristics of the Wolf-Rayet stars.

Two years ago the spectroscopic group at the Yerkes and McDonald observatories engaged in a large program of observations of all types of outer envelopes which are not accounted for by the elementary theories of stellar atmospheres. The problem of the Wolf-Rayet stars was included in this program, as it was believed that additional observational material might clarify our general ideas regarding the chemical constitution, the geometrical and dynamical picture, and the essential physical processes of these hot stars.

Additional observations were especially desirable in four directions: the southern Wolf-Rayet stars, some of which had been obtained with slitless spectrographs, and dis-

* Contributions from the McDonald Observatory, University of Texas, No. 40. This paper was presented at the symposium on astronomical spectra held at the Yerkes Observatory in celebration of the Fiftieth Anniversary of the University of Chicago on September ro-r2, I94I.

I Pub. Dom.Ap.Obs., 4, 271, 1930; 6, 95, 1934; M.N., 90, 202, 1929; 92, 577, 1932; J.R.A.S.Canada, 34, I69, I940; Observatory, 64, 42, I94I.

${ }^{2} M . N ., 81,142$, I920. Perrine already considers in some detail the different behavior of $\lambda 4634$ and $\lambda_{464 \mathrm{I}}(N \mathrm{III})$, on one hand, and of $\lambda 4650$ ( $\left.C \mathrm{III}\right)$, on the other.

${ }^{3} M . N ., 80,534$, 1920.

${ }_{4}$ Pub. Dom. Ap. Obs., 2, 346, I924.

$5 Z s . f$. Ap., 7, 378, I933; this paper contains the applications of Edlén's laboratory work to the identification of lines in $\mathrm{W}$ stars.

${ }^{6}$ Trans. I.A.U., 6, 248, 1938.

7 Zs.f. Ap., 7, i, r933.

${ }^{8}$ Pub. A.S.P., 51, 55, г939; Ap. J., 91, 379, I940, and 91, 394, I940.

${ }_{9}$ Ap. J., 93, 202, I94I. 
cussed by C. H. Payne during the period I927-I933; ${ }^{\text {io }}$ the Wolf-Rayet nuclei of planetary nebulae, which had been the object of the remarkable pioneering investigations by Wright ${ }^{i x}$ but for which further progress was anticipated in view of the recent instrumental advances; the objects intermediate between the pure absorption $\mathrm{O}$ stars and the W stars, to supplement earlier work by Wright, ${ }^{12} \mathrm{H}$. H. Plaskett, ${ }^{13} \mathrm{~J}$. S. Plaskett, ${ }^{14}$ and C. H. Payne; ${ }^{15}$ and the Wolf-Rayet characteristics in novae, especially those of the slow type. ${ }^{16}$

In collaboration with $O$. Struve, we have already collected and discussed a fairly large amount of observational material. ${ }^{17}$ Although our program has not yet been completed, we shall give here the main general results as they appear at the present stage, together with a description of some new observational material. From the beginning of our program in 1939 we planned to investigate the profiles of the emission and absorption lines and this photometric work will be carried on in the near future.

\section{NEW OBSERVATIONAL DATA ON SOME WOLF-RAYET STARS}

For physical discussions of Wolf-Rayet stars it is useful to possess, besides the general table of Wolf-Rayet lines as published by Beals, detailed descriptions of individual objects. Such descriptions have been published by J. S. Plaskett for six stars (three WN's and three WC's, including Campbell's object +30 3639 ), by Wright for several planetary nuclei, by C. H. Payne for several southern stars, and by Struve and Swings for the nuclei of $+30^{\circ}{ }_{3} 639$, NGC 6543 , IC 4 I 8 , NGC 40 , IC 4997 , and HD I 67362 .

In this section we shall give additional data for several Wolf-Rayet stars which are not surrounded by visible nebulosity.

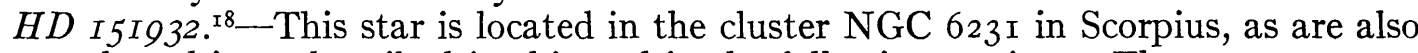
three other objects described in this and in the following section. ${ }^{19}$ The spectrum was described by C. H. Payne, ${ }^{20}$ together with several other stars in which both emission and absorption lines are present, the latter being strong and significant. Spectrograms of this star have been published by Beals, ${ }^{2 \mathrm{I}}$ who classified it as WN $7 .{ }^{22}$ For possible discussions of line widths, we have collected in Table I our measurements of this spectrum; these data could be added to the values of the line widths as given by Beals, and they confirm the well-established decrease in width with increasing ionization of the same atom. The sharpness of the $N \mathrm{v}$ lines is particularly conspicuous (Pl. IV, $a$ ).

זo Harvard Bull., Nos. 834, 836, 842, 843, 844, 855, 874, 878; Zs. f. Ap., 7, I, I933.

I $P$ ub. Lick Obs., 13, г93, г9г8; see also Stoy, Pub. A.S.P., 47, г62, г935.

${ }^{2}$ Op. cit., 206.

г3 Pub. Dom. Ap. Obs., r, 325, I922.

${ }^{4}$ Loc. cit.

${ }^{15}$ Harvard Bull., Nos. 842, 843, 844, I927.

${ }^{16}$ See Edlén's report to the Paris conference on novae and white dwarfs, r939.

${ }_{17}$ Papers published on this problem in collaboration with O. Struve: $A p$. J., 91, 546, 1940; 92, 289, I940; 92, 295, 1940; 93, 349, 1941; 93, 356, I94I; Proc. Nat. Acad. Sci., 26, 454, I940; 26, 458, I940; 26, 548, 'r940; 27, 225, г94I; Pub. A.S.P., 52, 394, г940; 53, 35, т941.

${ }^{18} \mathrm{CD}-4 \mathrm{I}^{\circ} \mathrm{I0972} ; m_{v}=6.56 ; a(\mathrm{r} 900)=\mathrm{r}^{6}{ }^{\mathrm{h}} 45^{\mathrm{m}} \cdot 3 ; \delta(\mathrm{I} 900)=-4 \mathrm{I}^{\circ} 4 \mathrm{r}^{\prime} ; \mathrm{WN}_{7}$ according to Beals. I most sincerely thank Mrs. C. Payne Gaposchkin, who called our attention to the W and $\mathrm{O}$ stars in NGC 623I.

19 For investigations of this cluster see D. A. MacRae, Harvard Bull., No. 9r4, p. 21, r940, and references to earlier publications mentioned in this paper. The distance of the $O$ stars appears to be 300 parsecs, and the photographic,absorption amounts to $1.7 \mathrm{mag}$.

${ }^{20}$ Harvard Bull., No. 843, I927.

${ }^{21}$ Trans. I.A.U., 6, 248, Pl. I, I938; J.R.A.S. Canada, 34, Pl. VIII, I940.

${ }^{22}$ WN6 would seem better, according to our spectrograms. 
TABLE 1

SPECTRUM OF HD I 5 I932 $\left.^{2} \mathrm{WN}_{7}\right)$

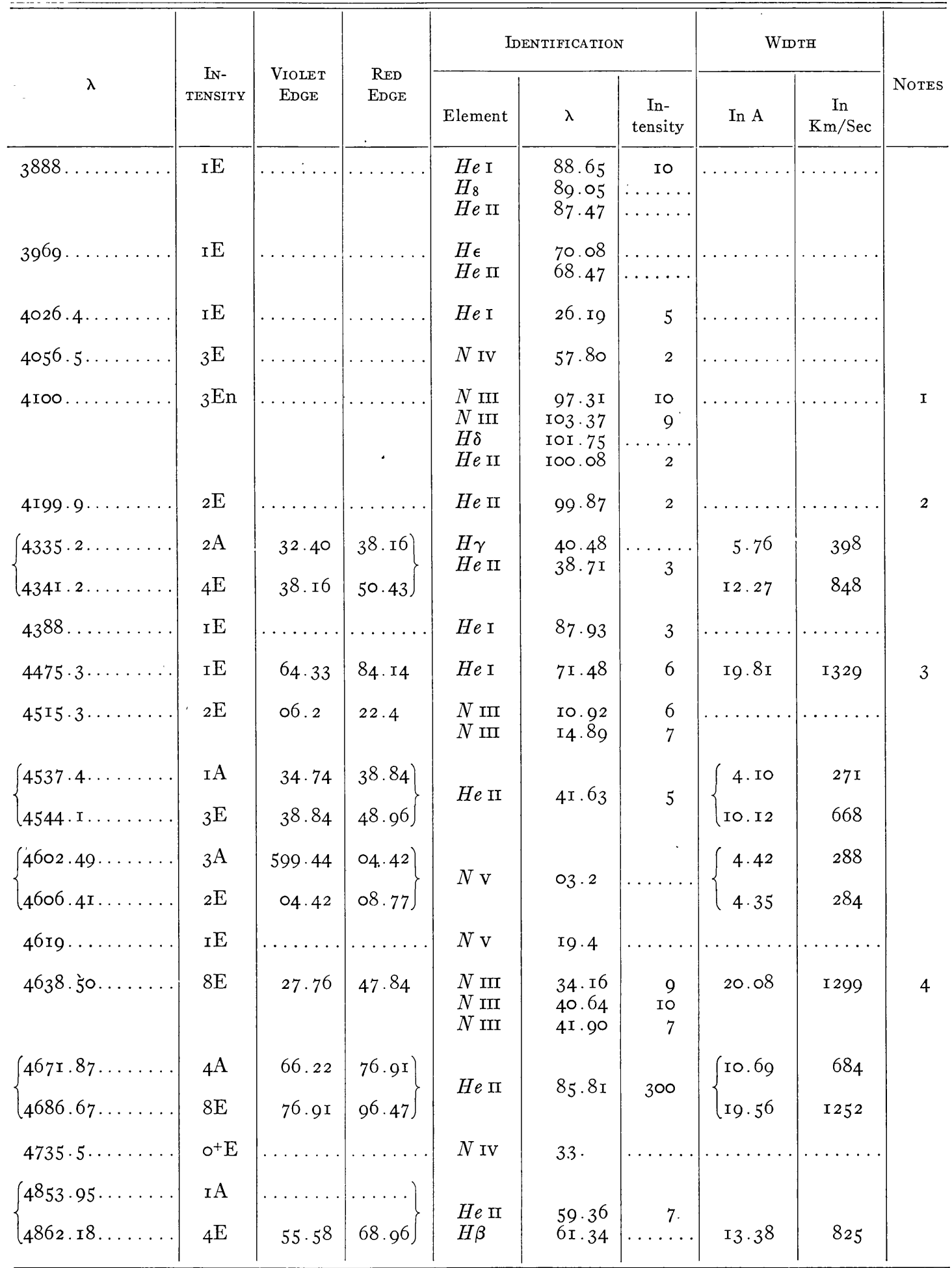


TABLE 1-Continued

\begin{tabular}{|c|c|c|c|c|c|c|c|c|c|}
\hline$\lambda$ & $\begin{array}{c}\text { IN- } \\
\text { TENSITY }\end{array}$ & $\begin{array}{c}\text { VIOLET } \\
\text { EDGE }\end{array}$ & $\begin{array}{l}\text { RED } \\
\text { EDGE }\end{array}$ & \multicolumn{3}{|c|}{ IDENTIFICATION } & \multicolumn{2}{|c|}{ WITTH } & Notes \\
\hline
\end{tabular}

NOTES TO TABLE 1 lines.

The wave lengths given in the first column correspond to the maxima of the emission or absorption

I. Very broad feature.

2. Possibly double.

3. Violet absorption probably present.

4. In $\lambda_{4638}$, two maxima are observed corresponding to $N$ III 4634 and $N$ III 464r. The presence of a faint line near $C$ iv 4658 is not excluded.

5. Double emission; central minimum at $\lambda$ 5413.9.

6. Strong violet absorption present.

$H D I 92163^{23}$-Although this star is a typical representative of class WN6, all the lines are not identified with certainty $(\mathrm{Pl} . \mathrm{IV}, b)$. This is especially true of a fairly strong line situated to the blue of $\mathrm{He}$ I 5876 . The wave length of this line was measured by J. S. Plaskett in HD I92 I63 at $\lambda$ 58 $^{8} 2$ (intensity 4, compared to intensity 6 for $\mathrm{He}_{\mathrm{I}} 5^{8} 7_{7} 6$ and intensity I 4 for $H e$ II 54II). The other measures collected by Beals were $\lambda_{5807}$ (Campbell), $\lambda_{5807}$ (Wright), and $\lambda_{5806}$ (Beals), and he finally adopted the value $\lambda{ }_{5806}$. We measured the same band on an excellent spectrogram and obtained $\lambda_{5803}$ for the center of the emission.

The exact wave length is certainly very near $\lambda_{5805}$, and it cannot be shifted appreciably in either direction, since the violet-absorption component of the measured line is absent or extremely weak and since the violet-absorption component of $D_{3} 5^{8} 76$ is fairly sharp and does not extend to the blue beyond $\lambda 5^{8} 42$.

The line is observed in the nitrogen sequence where it reaches its maximum in the subclass WN6; it is still observed in WN7. It has been attributed by Beals to a predicted transition of $N$ IV, whereas Edlén ${ }^{24}$ had identified it tentatively with $C \operatorname{Iv}($ ?). The predicted multiplet of $N$ IV considered by Beals is $3 \mathrm{p}^{\prime}{ }^{3} \mathrm{P}-3 \mathrm{~d}^{\prime}{ }^{3} \mathrm{P}^{\circ}$ (excitation potential of upper level 63.I volts). Although the transition has not been observed in the laboratory, the relative values of the levels are fairly well known; actually $3 \mathrm{~d}^{\prime}{ }^{3} \mathrm{P}^{0}$ combines with $2 \mathrm{p}^{\prime}{ }^{3} \mathrm{P}$ (strong group at $\lambda 298$ ), which in turn combines with $2 \mathrm{p}^{3} \mathrm{P}^{\circ}$ (strong group near $\lambda_{923}$ ) and $3 \mathrm{~s}^{\prime}{ }^{3} \mathrm{P}^{\circ}$ (intense lines near $\lambda 345$ ). Finally, the transitions between these last two levels and $3 \mathrm{p}^{\prime} 3 \mathrm{P}$ have been observed in the laboratory. The uncertainty in the relative positions of the levels $3 \mathrm{p}^{\prime}{ }^{3} \mathrm{P}$ and $3 \mathrm{~d}^{\prime}{ }^{3} \mathrm{P}^{0}$ thus results mostly from possible errors of measurement in the vacuum ultraviolet multiplets. But, considering the precision of

${ }_{23} \mathrm{BD}+37^{\circ} 382 \mathrm{I} ; a(\mathrm{I} 900)=20^{\mathrm{h}} 8^{\mathrm{m}} \cdot 4 ; \delta(\mathrm{I} 900)=+3^{\circ} \circ 3^{\prime} ; \mathrm{WN} 6$ according to Beals.
${ }^{24}$ Zs.f. Ap., 7, 378, 1933. 
Edlén's measures of the $N$ IV spectrum, it does not appear possible to accept an error of more than $5 \mathrm{~A}$ in the predicted wave lengths. These are given in Table $2 .{ }^{24}$ The center of gravity of the three broad lines should thus be around $\lambda 5^{8} 30,25$ and it does not seem possible to explain the difference of $25 \mathrm{~A}$ between the predicted wave lengths and the wave length measured in HD I92I63. The predicted multiplet should be much weaker than the "unprimed" transition $3 \mathrm{~S}^{3} \mathrm{~S}-3 \mathrm{p}^{3} \mathrm{P}^{0}$ (near $\lambda 348 \mathrm{I}$ ) and $3 \mathrm{P}^{\mathrm{x}} \mathrm{P}^{0}-3 \mathrm{~d}^{\mathrm{D}} \mathrm{D}$ $(\lambda$ 4057.8). Additional laboratory work would be most valuable.

Under the present conditions it appears more logical to attribute the line to the $3 \mathrm{~s}^{2} \mathrm{~S}-3 \mathrm{P}^{2} \mathrm{P}^{0}$ transition of $C$ IV (excitation potential of $3 \mathrm{p}^{2} \mathrm{P}^{0}, 39.5$ volts); the laboratory wave lengths are $\lambda_{580 \mathrm{I} .5 \mathrm{I}}$ (intensity 4 ) and $\lambda_{58 \mathrm{I}}$ 2.I 4 (intensity 3 ). This doublet is the most striking characteristic of $C$ IV in WC stars, the other (corresponding to the much higher excitation potential of 58 volts and to higher $n$-values) being $5 g^{2} \mathrm{G}^{0}-6 \mathrm{~h}^{2} \mathrm{H}$ at $\lambda{ }_{46} 5^{8.64}$ and $5^{2} \mathrm{~F}-6 \mathrm{~g}^{2} \mathrm{G}^{0}$ at $\lambda{ }_{4656.5}$. Unfortunately, in nitrogen stars, these blue

TABLE 2

Predicted Wave Lengths and Theoretical Relative Intensities OF THE $3 \mathrm{P}^{\prime} 3 \mathrm{P}-3 \mathrm{~d}^{\prime} 3 \mathrm{P}^{\circ}$ TRANSITIONS IN $N$ iV

\begin{tabular}{|c|c|c|c|c|c|}
\hline & $\lambda$ & Intensity & & $\lambda$ & Intensity \\
\hline $\begin{array}{l}3 \mathrm{P}^{\prime}{ }^{3} \mathrm{P}_{\mathrm{I}}-3 \mathrm{~d}^{\prime} 3 \mathrm{P}_{2}^{0} \ldots \ldots \\
3 \mathrm{P}^{\prime}{ }_{3} \mathrm{P}_{2}-3 \mathrm{~d}^{\prime} 3 \mathrm{P}_{\mathrm{I}}^{0} \ldots \ldots\end{array}$ & $\begin{array}{l}5812 \\
5828\end{array}$ & $\begin{array}{l}5 \\
5\end{array}$ & $3 \mathrm{p}^{\prime}{ }_{3} \mathrm{P}_{2}-3 \mathrm{~d}^{\prime}{ }_{3} \mathrm{P}_{2}^{0} \ldots \ldots$ & 5846 & I5 \\
\hline
\end{tabular}

lines would fall between $H e$ II 4686 and the group of nitrogen lines $\lambda \lambda{ }_{4603}(N \mathrm{v}), 46$ I9 $(N \mathrm{v}), 4634$ ( $N$ III) , 464I ( $N$ III), so that their detection is extremely difficult. ${ }^{26}$ Besides,

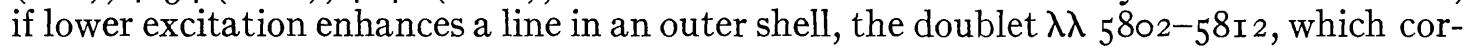
responds to an excitation potential is volts lower than $\lambda_{46} 68$, would be relatively enhanced. In their theoretical synthesis of supernova spectra, Whipple and C. P. Gaposchkin consider $\lambda_{5} 806$ as very much stronger than the group near $\lambda_{4} 65_{5,}{ }^{27}$ this being in consequence of the lower $n$-values.

The ionization potential of $\mathrm{C}^{+++}$being 64.2 volts as compared to 47.2 volts for $\mathrm{N}^{++}$ and 77.0 volts for $N^{+++}$, it is natural that the line $\lambda 5805$, if due to $C$ IV, should reach its maximum in the same subclass as $N$ IV (WN6) but should still be present in WN7.

The $C$ IV doublet is usually observed as a broad band in WC stars; but in some cases the two components are well separated, i.e., in the nuclei of NGC $6543^{28}$ and in Campbell's envelope star. In the latter case Wright ${ }^{29}$ measured three lines at $\lambda \lambda 5^{80 I}$, 581 2, and 5828; the first two belong to $C$ IV and the third to $C$ III.

${ }^{25}$ This value was also adopted by Whipple and C. P. Gaposchkin in their theoretical synthesis of the supernova spectra, Proc. Amer. Phil. Soc., 84, I, I94I.

${ }^{26}$ According to our measurements, the red wing of the broad emission observed in HD I92163, with maximum around $4638 \mathrm{~A}$ seems to extend too far to be attributed to $N$ III only; there may thus be some blending effect by $C$ III and $C$ IV in the red wing. Actually, in the same spectrum, J. S. Plaskett measured two maxima in the broad band near $\lambda 4640$, one of intensity ro at $\lambda_{46}{ }^{2}$ ( $N$ III), the other of intensity 6 at $\lambda{ }_{4652}(C \mathrm{II}, C \mathrm{IV})$; but this difficult observation remains somewhat doubtful.

${ }_{27}$ Because of blends, the only $6 \rightarrow 5$ transitions of $C$ IV observed by Edlén in the laboratory were

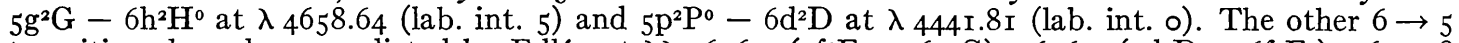
transitions have been predicted by Edlén at $\lambda \lambda{ }_{4} 6{ }_{5} 6.5\left({ }_{5} \mathrm{f}^{2} \mathrm{~F}^{0}-6 \mathrm{~g}^{2} \mathrm{G}\right), 4646.5\left({ }_{5} \mathrm{~d}^{2} \mathrm{D}-6 \mathrm{f}^{2} \mathrm{~F}^{0}\right), 4659.38$ $\left(5 \mathrm{~g}^{2} \mathrm{G}^{0}-6 \mathrm{f}^{2} \mathrm{~F}^{0}\right)$, and $4664.5\left(5^{2} \mathrm{~F}^{0}-6 \mathrm{~d}^{2} \mathrm{D}\right)$. By analogy to the relative laboratory intensities observed among the $5 \rightarrow 4$ transitions, it appears that $\lambda_{46} 68.64$ must be the strongest of the $6 \rightarrow 5$ transitions, the intensities among the lines to the blue of $\lambda 4658.64$ decreasing with decreasing quantum number $L$. This is opposite to what Whipple and C. P. Gaposchkin have adopted in their work on supernovae.

${ }^{28}$ R. H. Stoy, Lick Obs. Bull., I7, 179, I935; P. Swings, Ap. J., 92, 289, r940.

29 Op. cit., p. 193, 1918. 
The conclusion to be drawn is that in some WN stars there is rather conclusive evidence in favor of the presence of carbon lines, although nitrogen is more abundant: only additional laboratory work would settle the matter definitely. But it will be shown in section III that the simultaneous presence of $C$ and $N$ is by no means exceptional in planetary nuclei of Wolf-Rayet type.

$H D I 52270.3^{\circ}$-This object is also located in the cluster NGC 623I. Its spectrum was described by C. H. Payne, ${ }^{3 \mathrm{I}}$ who identified $H e$ II, $C$ III, $C$ IV, $N$ IV, and $N$ v. Although these identifications have to be revised, the description by Miss Payne is very important, because she called attention to the central reversals which were present in certain lines, in addition to the violet absorptions. This observation, which will be discussed in section III, has not received the attention it deserves and will eventually help in understanding the physical processes involved.

The following lines are observed on our spectrograms $(\mathrm{Pl} . \mathrm{V}, b)$ :

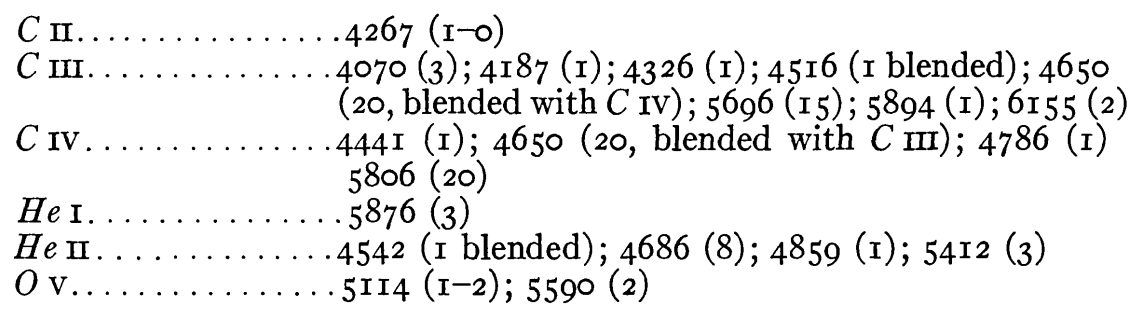

The central undisplaced reversal is present in all Balmer lines and in several lines of

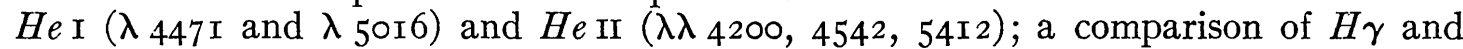
$H e$ I $447 \mathrm{I}$ shows that the central absorption is sharper in $H e \mathrm{I}$ than in $H$. Similarly the central absorptions are sharper for $H e$ II than for $H$. In the region of the higher members of the Balmer series the wings of the Balmer emissions overlap, so that only the central absorptions appear clearly, and these may be followed to $H_{\mathrm{r} 3}$. There is no appreciable reversal in $C$ III $4070, C$ III $+C$ IV $4650, C$ III 5696 or $H e$ II 4686.

As usual, the $C$ III lines are much broader (width of $C$ III $5696: 72.5 \mathrm{~A}$ or $3800 \mathrm{~km} / \mathrm{sec}$ ) than the $C$ IV lines (width of the blend of $\lambda$ 580I and $\lambda_{58}$ I 2 of $C$ IV: 5 I.8 A; this width would have been reduced to about $45 \mathrm{~A}$ or about $23 \mathrm{co} \mathrm{km} / \mathrm{sec}$ if the line had been simple).

According to the intensity ratios (and to the line widths), the star should really be considered as intermediate between $\mathrm{WC} 6$ and $\mathrm{WC}_{7}$ and might be called WC6+. According to the intensity criteria adopted by the International Astronomical Union, the object is later than WC6; but compared with the typical $\mathrm{WC}_{7}$ star-HD I92 I03 $(\mathrm{Pl}$. $\mathrm{V}, a)$-the intensity ratio of $H e \mathrm{I} 5876$ and $C \mathrm{IV} 5806$ is smaller in this star.

$H D_{16} 6270 . .^{32}$-This object has a remarkable Wolf-Rayet spectrum in which both emission and absorption lines are present $\left(\mathrm{Pl}\right.$. V, c). It was described by $\mathrm{C}$. H. Payne, ${ }^{33}$ who noticed that the widths of the lines were of the order of ro A. Since our material appears to be better than Payne's and since the identifications may now be improved, our measured wave lengths are collected in Table 3 . Unidentified lines have been measured at $\lambda \lambda{ }_{445} \mathrm{I} .6$ (I), 5092.9 (I), and $547 \mathrm{I} .0$ (5); they are also present in $\mathrm{BD}+30^{\circ} 3639$. Another unidentified line at $\lambda 6410.5$ was also observed in HD I92103. Except for the fact that the lines are broader, the present object is very similar to $+30^{\circ} 3639$ and constitutes an excellent example of a WC8 star.

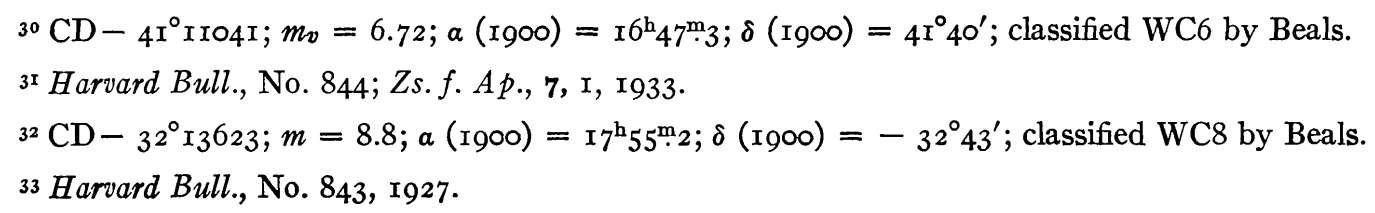




\section{P. SWINGS}

TABLE 3

SPECTRUM OF HD I64270 (WC8)

\begin{tabular}{|c|c|c|c|c|c|c|c|c|c|}
\hline \multirow{2}{*}{$\lambda$} & \multirow{2}{*}{$\underset{\text { TENSITY }}{\text { IN- }}$} & \multirow{2}{*}{$\begin{array}{l}\text { VIOLET } \\
\text { EDGE }\end{array}$} & \multirow{2}{*}{$\begin{array}{l}\text { RED } \\
\text { EDGE }\end{array}$} & \multicolumn{3}{|c|}{ IDENTIFICATION } & \multicolumn{2}{|c|}{ Wmтн } & \multirow{2}{*}{ Notes } \\
\hline & & & & Element & $\lambda$ & $\begin{array}{c}\text { In- } \\
\text { tensity }\end{array}$ & In $\mathrm{A}$ & $\underset{\mathrm{Km} / \mathrm{Sec}}{\mathrm{In}}$ & \\
\hline $3888.7 \ldots \ldots$ & $3 \mathrm{E}$ & $8 \mathrm{I} \cdot 72$ & $94 \cdot 40$ & $\begin{array}{l}H e \mathrm{I} \\
C \text { III } \\
C \text { III }\end{array}$ & $\begin{array}{l}88.65 \\
89.18 \\
85.99\end{array}$ & $\begin{array}{r}\text { ro } \\
4 \\
3\end{array}$ & $\mathrm{I}_{5} .68$ & I 209 & I \\
\hline $3923.3 \ldots \ldots$ & $3 \mathrm{E}$ & I $2 \cdot 32$ & $33 \cdot 4 \mathrm{I}$ & $\begin{array}{l}C \text { II } \\
C \text { II } \\
H e \text { II }\end{array}$ & $\begin{array}{l}\text { I } 8.98 \\
20.68 \\
23.5^{1}\end{array}$ & $\begin{array}{c}9 \\
\text { Io } \\
\ldots \ldots\end{array}$ & 21.09 & I6I I & \\
\hline $3960.9 \ldots \ldots \ldots$ & IEnn & $\ldots \ldots$ & $\ldots \ldots$ & $\begin{array}{l}O \text { III } \\
H e \mathrm{I}\end{array}$ & $\begin{array}{l}6 r \cdot 59 \\
64.73\end{array}$ & $\begin{array}{l}8 \\
4\end{array}$ & & 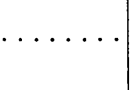 & \\
\hline $4026.5 \ldots \ldots \ldots$ & $2-3 E$ & 20.38 & 35.63 & $\begin{array}{l}\mathrm{He} \mathrm{II} \\
\mathrm{He} \mathrm{I}\end{array}$ & $\begin{array}{l}25.64 \\
26.19\end{array}$ & $\cdots \cdots$ & $\mathrm{I} 5.25$ & I I36 & \\
\hline $4055 \cdot 5 \ldots \ldots \ldots$ & $3 \mathrm{E}$ & $50.6 I$ & 59.80 & $C$ III & $5^{6.06}$ & 5 & 9.19 & 680 & \\
\hline 407 I.6..... & ${ }_{5} \mathrm{E}$ & 64.94 & 78.06 & $\begin{array}{l}C \text { III } \\
C \text { III } \\
C \text { III } \\
O \text { II } \\
C \text { II } \\
C \text { II } \\
C \text { II }\end{array}$ & $\begin{array}{l}67.87 \\
68.97 \\
70.30 \\
75.87 \\
76.00 \\
74.89 \\
74.53\end{array}$ & $\begin{array}{r}9 \\
\text { 10 } \\
\text { 10 } \\
\text { 10 } \\
7 \\
5 \\
6\end{array}$ & I $3 \cdot$ I 2 & 967 & 2 \\
\hline $4088.8 \ldots$ & ${ }_{2} \mathrm{E}$ & 84.85 & $93 \cdot$ I I & $S i \mathrm{IV}$ & 8.86 & Io & 8.26 & 606 & \\
\hline 4099. I...... & $\mathrm{IE}$ & $95 \cdot 24$ & IOI .86 & $\begin{array}{l}H \delta \\
H e \mathrm{II}\end{array}$ & $\begin{array}{l}\text { IoI. } 76 \\
\text { Ioo. } 08\end{array}$ & $\ldots$ & 6.62 & 484 & \\
\hline $4122.7 \ldots \ldots \ldots$ & ${ }_{4} \mathrm{E}$ & I 2.85 & $29 \cdot 54$ & $\begin{array}{l}\mathrm{Si} \mathrm{IV} \\
\mathrm{He} \mathrm{I} \\
\mathrm{C} \mathrm{III}\end{array}$ & $\begin{array}{l}\text { I6. I0 } \\
20.81 \\
22.05\end{array}$ & $\begin{array}{l}8 \\
3 \\
3\end{array}$ & I6.69 & $\mathrm{I} 2 \mathrm{I} 3$ & \\
\hline $4 \mathrm{I} 6 \mathrm{I} .2 \ldots$ & ${ }_{4} \mathrm{E}$ & $49 \cdot 34$ & 70.15 & $\begin{array}{l}C \text { III } \\
C \text { III }\end{array}$ & $\begin{array}{l}62.80 \\
56.50\end{array}$ & $\begin{array}{l}5 \\
4\end{array}$ & $20.8 \mathrm{I}$ & I 500 & \\
\hline $4 \mathrm{r} 86.8 \ldots \ldots$ & $5 \mathrm{E}$ & $8 I \cdot 3 I$ & $93 \cdot 33$ & $\begin{array}{l}C \text { III } \\
O \text { II }\end{array}$ & $\begin{array}{l}87.05 \\
89.79\end{array}$ & $\begin{array}{l}\text { Io } \\
\text { Io }\end{array}$ & $\mathrm{I} 2.02$ & $86 I$ & 2 \\
\hline $4200.0 \ldots \ldots$ & $\mathrm{IE}$ & & $\ldots \ldots$ & $H e \mathrm{II}$ & I99. 87 & $\cdots$ & . & $\ldots \ldots$ & \\
\hline $4267 \cdot 5 \ldots$ & $8 \mathrm{E}$ & $5^{8.23}$ & $77 \cdot 78$ & $\begin{array}{l}C \text { II } \\
C \text { II }\end{array}$ & $\begin{array}{l}67.27 \\
67.02\end{array}$ & $\begin{array}{l}20 \\
19\end{array}$ & $\mathrm{x} 9 \cdot 55$ & I374 & \\
\hline $4325.0 \ldots \ldots$ & $6 \mathrm{E}$ & x6.05 & $33 \cdot 50$ & $C$ III & $25 \cdot 70$ & 8 & $\mathrm{I} 7.45$ & I 209 & \\
\hline $4339 \cdot 4 \ldots \ldots \ldots$ & $\mathrm{IE}$ & $\ldots \ldots$ & $\ldots \ldots$ & $\begin{array}{l}H e \text { II } \\
H \gamma\end{array}$ & $\begin{array}{l}38.7 I \\
40.48\end{array}$ & & & & \\
\hline $4367 \cdot 3 \ldots \ldots$ & $3 \mathrm{E}$ & 6 I. 75 & $72 \cdot 5^{I}$ & $C$ III & 68.14 & 4 & I0. 77 & 740 & \\
\hline $4385.8 \ldots$ & $3 \mathrm{E}$ & $75 \cdot 7 \mathrm{x}$ & 95.65 & $\begin{array}{l}H e \text { I } \\
C \text { III } \\
C \text { III }\end{array}$ & $\begin{array}{l}87.93 \\
88.24 \\
83.24\end{array}$ & $\begin{array}{l}3 \\
2 \\
\mathrm{I}\end{array}$ & I9.96 & I 365 & \\
\hline
\end{tabular}


TABLE 3-Continued

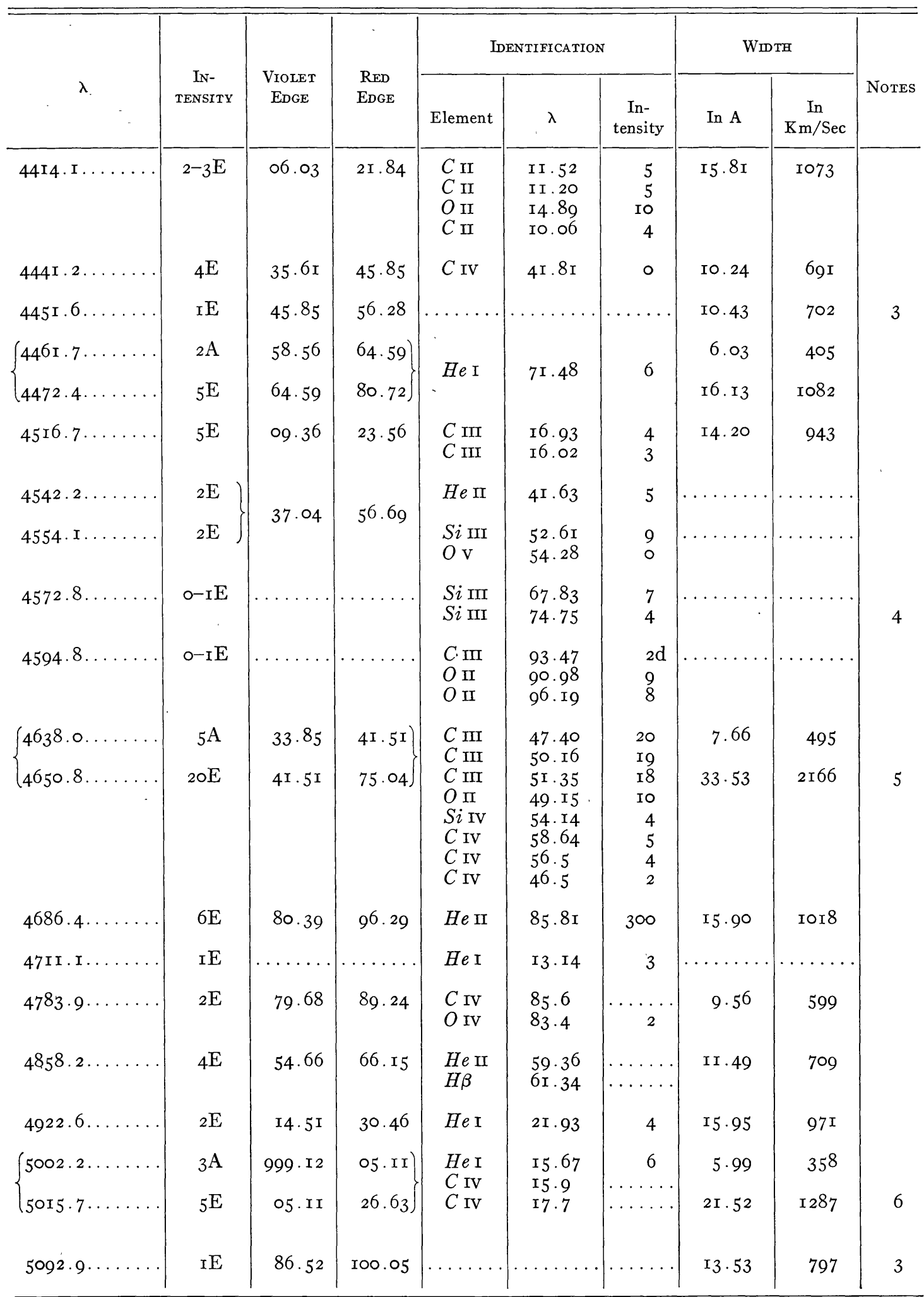


TABLE 3-Continued

\begin{tabular}{|c|c|c|c|c|c|c|c|c|c|}
\hline \multirow{2}{*}{$\lambda$} & \multirow{2}{*}{$\begin{array}{c}\text { IN- } \\
\text { TENSITY }\end{array}$} & \multirow{2}{*}{$\begin{array}{l}\text { VIOLET } \\
\text { EDGE }\end{array}$} & \multirow{2}{*}{$\begin{array}{l}\text { RED } \\
\text { EDGE }\end{array}$} & \multicolumn{3}{|c|}{ IDENTI FICATION } & \multicolumn{2}{|c|}{ WmTH } & \multirow[b]{2}{*}{ Notes } \\
\hline & & & & Element & $\lambda$ & $\begin{array}{c}\text { In- } \\
\text { tensity }\end{array}$ & In $\mathrm{A}$ & $\underset{\mathrm{In}}{\mathrm{In} / \mathrm{Sec}}$ & \\
\hline $5 \mathrm{I} 33.2 \ldots \ldots$ & $7 \mathrm{E}$ & 24.16 & 42.63 & $\begin{array}{l}(C \text { II } \\
(C \text { II }\end{array}$ & $\begin{array}{l}32.96 \\
33.29\end{array}$ & $\begin{array}{l}\text { 3) } \\
\text { 2) }\end{array}$ & I 8.47 & 1080 & 7 \\
\hline $5244 \cdot 3 \ldots \ldots \ldots$ & $\mathrm{IE}$ & 40.37 & 56.42 & $C$ III & $44 \cdot 5$ & $\circ$ & & & \\
\hline $5252 . x \ldots \ldots$ & $3 \mathrm{E}$ & T. & & $\begin{array}{l}C \text { III } \\
C \text { III }\end{array}$ & $\begin{array}{l}53.55 \\
49.6\end{array}$ & $\begin{array}{l}\mathrm{r} \\
0\end{array}$ & $\ldots \ldots$ & , & \\
\hline $5272.3 \ldots \ldots$ & $3 \mathrm{E}$ & 65.88 & 76.37 & $C$ III & $72 \cdot 5^{6}$ & 2 & I0. 49 & 597 & \\
\hline $5304.67 \ldots \ldots$ & ${ }_{4} \mathrm{E}$ & 298.24 & $09 \cdot 30$ & $(O \mathrm{IV}$ & 05 & pr) & I I.06 & 626 & 3 \\
\hline $5343 \cdot 3 \ldots \ldots$ & IE & $\ldots$. & $\ldots \ldots$ & $(C \mathrm{II}$ & 36.7 & o) & $\cdots \cdots$ & 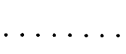 & \\
\hline $54 \mathrm{I} 3.9 \ldots \ldots$ & $5 \mathrm{E}$ & $05 \cdot 59$ & $2 \mathrm{I} .20$ & $\mathrm{He} \mathrm{II}$ & II .57 & $\cdots$ & $\mathrm{I} 5 \cdot 6 \mathrm{I}$ & 866 & 8 \\
\hline 547 I.०....... & $5 \mathrm{E}$ & 64.62 & $75 \cdot 30$ & $\ldots \ldots$ & $\ldots \ldots$ & $\ldots \ldots$ & 10.68 & 586 & 9 \\
\hline 5596. I....... & $3 \mathrm{E}$ & 88.00 & $601 \cdot 74$ & $\begin{array}{l}O \mathrm{III} \\
O \mathrm{v}\end{array}$ & $\begin{array}{l}92.37 \\
97.9\end{array}$ & $\begin{array}{l}6 \\
\cdots\end{array}$ & $13 \cdot 74$ & 736 & \\
\hline $5650.8 \ldots \ldots$ & $\mathrm{IE}$ & 33.12 & 65.05 & $\begin{array}{l}C \text { II } \\
C \text { II }\end{array}$ & $\begin{array}{l}48.08 \\
62.51\end{array}$ & $\begin{array}{l}3 \\
4\end{array}$ & $31 \cdot 93$ & r695 & \\
\hline$\left\{\begin{array}{l}5668.8 \ldots \ldots \\
5697.2 \ldots \ldots \ldots\end{array}\right.$ & $\begin{array}{l}\text { IA? } \\
{ }_{5} \mathrm{E}\end{array}$ & $\begin{array}{l}\ldots \ldots \\
76.53\end{array}$ & $\left.\begin{array}{c}\ldots \ldots \\
7 \mathrm{I} 4 \cdot 23\end{array}\right\}$ & $C \mathrm{III}$ & 96.0 & 8 & $37 \cdot 70$ & I987 & \\
\hline $5789.2 \ldots$ & $4 \mathrm{~A}$ & 82.67 & $94 \cdot 54$ & $\begin{array}{l}C \text { IV } \\
C \text { IV }\end{array}$ & $\begin{array}{l}\text { OI. } 5 \text { I } \\
\text { I2.I4 }\end{array}$ & $\begin{array}{l}4 \\
3\end{array}$ & & & IO \\
\hline 5822.2. & IOE & $794 \cdot 54$ & $4 \mathrm{I} \cdot 93$ & $C \mathrm{III}$ & $27 \cdot I$ & I & $47 \cdot 39$ & 2442 & \\
\hline $5860 \cdot 3 \ldots$ & $2 \mathrm{~A}$ & & & $\begin{array}{l}H e \mathrm{I} \\
C \mathrm{II}\end{array}$ & $\begin{array}{l}75.62 \\
91.65\end{array}$ & $\begin{array}{r}\text { 10 } \\
3\end{array}$ & & & \\
\hline $5880.2 \ldots$ & IoE & 65.65 & $905 \cdot 45$ & $\begin{array}{l}C \text { II } \\
C \text { III } \\
C \text { III }\end{array}$ & $\begin{array}{l}89.97 \\
7 \text { I. } 6 \\
94.1\end{array}$ & $\begin{array}{r}4 \\
\mathrm{pr} \\
\mathrm{pr}\end{array}$ & 39.80 & 2030 & II \\
\hline $6 \mathrm{ro2} .8 \ldots$ & $\mathrm{IE}$ & & & $\begin{array}{l}C \text { II } \\
C \text { II }\end{array}$ & $\begin{array}{l}98.62 \\
95 \cdot 37\end{array}$ & $\begin{array}{l}3 \\
2\end{array}$ & & & \\
\hline $6 \mathrm{I}_{54} .8 \ldots$ & $4 \mathrm{E}$ & & . & $\begin{array}{l}C \text { III } \\
C \text { III } \\
C \text { III }\end{array}$ & $\begin{array}{l}54 \cdot 4 \\
55 \cdot 4 \\
56 \cdot 7\end{array}$ & $\begin{array}{l}\mathrm{pr} \\
\mathrm{pr} \\
\mathrm{pr}\end{array}$ & & & \\
\hline $6207.1 \ldots \ldots$ & $2 \mathrm{E}$ & & & & $\cdots$ & & & & 3 \\
\hline 64 Io. $5 \ldots \ldots$ & $2 \mathrm{E}$ & & & & & & & & I 2 \\
\hline $6464.2 \ldots \ldots \ldots$ & $4 \mathrm{E}$ & & & & & & & & 3 \\
\hline
\end{tabular}


TABLE 3-Continued

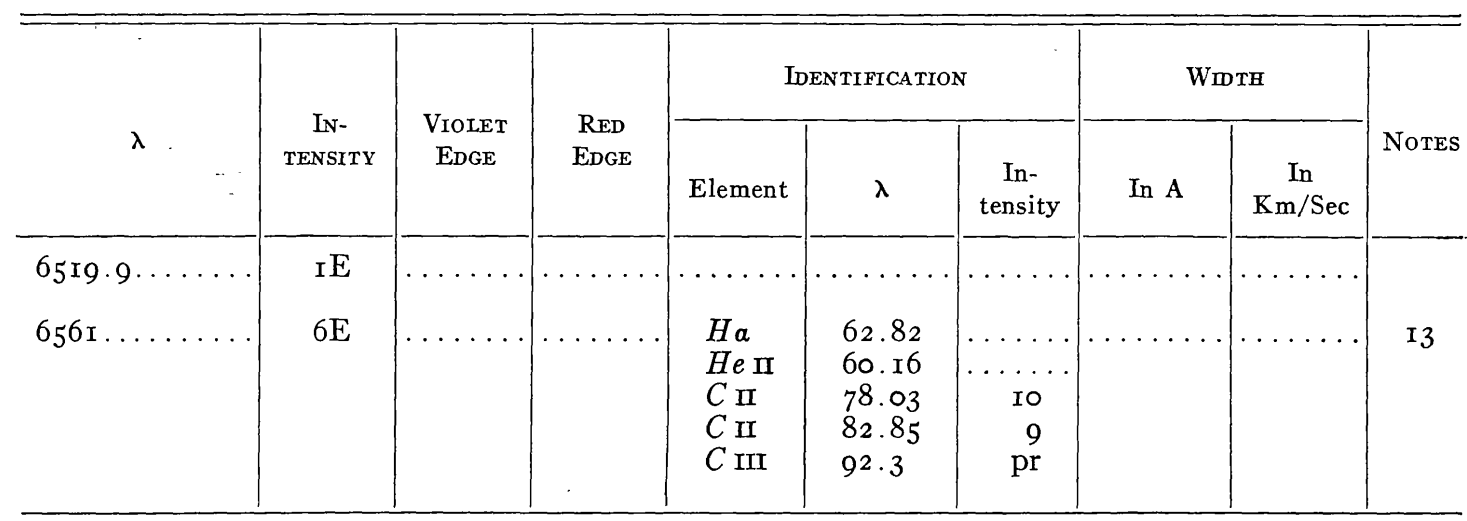

NOTES TO TABLE 3

I. Fairly strong violet absorption.

2. May have a weak violet absorption.

3. Also present in $\mathrm{BD}+30^{\circ} 3639$.

4. Uncertain.

5. A secondary maximum at $\lambda 4665.9$ corresponds to $\lambda \lambda 4665.90$ ( $C$ III, int. 6$), 4663.53$ ( $C$ mI, int. 4), 4664.5 ( $C$ IV, int. I), and 466r.65 (O II, int. 9).

6. Probably a broad line to the red of $\lambda_{5026}$.

7. $\lambda_{5}{ }^{\mathrm{I}} 33$ is superposed on a broader line of intensity IEn extending from 5 I 14.3 to 5 r 64.3 and due (at least partly) to a blend of $C$ II lines $\left(\lambda \lambda_{5}\right.$ Ir 4.07 [2], I9.55 [2], 21.69 [r], 43.49 [2], 45.16 [5]). In $\mathrm{BD}+30^{\circ} 3639$, Wright mentions a group of two or more faint emission bands below $\lambda \mathrm{I}^{\mathrm{I}} 3 \mathrm{I}$ and extending to about $\lambda_{5} \mathrm{I} 62$.

8. Weak violet absorption present.

9. One of the strongest unidentified lines.

Io. The three components are separated in $\mathrm{BD}+30^{\circ} 3639$.

II. Violet edge much sharper than red edge.

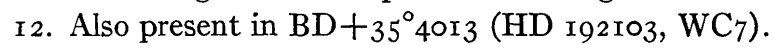

I3. Broad and complex band.

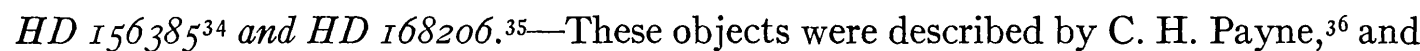
the second was also observed by Beals. In agreement with Beals, they must be classified as carbon stars $(\mathrm{Pl} . \mathrm{V}, d)$. No nitrogen line was observed in our spectrograms, contrary to identifications suggested by $\mathrm{C}$. H. Payne. ${ }^{37}$

In $\mathrm{HD}$ I68206 there may be a central reversal in $H e$ II 4542. The spectrum of this star is mainly characterized by strong $C$ III, $\lambda{ }_{5696}$ being stronger than $C$ IV $58 \mathrm{c} 6 ; H e$ II is weak, and $H e \mathrm{I}$, as well as $H$, is very weak.

\section{NEW DATA ON THREE OBJECTS INTERMEDIATE BETWEEN WOLF-RAYET AND ABSORPTION O STARS}

Several typical examples of objects showing an absorption spectrum of $O$ type, on which are superposed vestiges of emission, have been described previously, ${ }^{38}$ for example,

${ }^{34} \mathrm{CD}-45^{\circ} \mathrm{II} 392 ; m=7.2 ; a(\mathrm{I} 900)=\mathrm{I} 7^{\mathrm{h}} \mathrm{I} 2^{\mathrm{m}} \cdot \mathrm{I} ; \delta(\mathrm{r} 900)=-45^{\circ} 32^{\prime} ;$ classified as WC6 by Beals.

${ }_{35} \mathrm{BD}-\mathrm{II}^{\circ} 4593 ; m=8.9 ; a(\mathrm{I} 900)=\mathrm{I}^{\mathrm{h}}{ }_{1} 3^{\mathrm{m}} \cdot 5 ; \delta(\mathrm{I} 900)=-\mathrm{II}^{\circ} 40^{\prime} ;$ classified as $\mathrm{WC}_{7}$ by Beals.

${ }^{36}$ Harvard Bull., No. 844, I927.

37 Zs.f. Ap., 7, г, г933.

${ }^{8} 8$ Ap. J., 91, 553, I940, and earlier references mentioned there; Pub. A.S.P., 52, 394, I940 (HD I92639); 53, 35, I94I (HD I08); Proc. Nat. Acad., 27, 225, I94I (IC 4I8). 
9 Sagittae, $\mathrm{BD}+35^{\circ} 3930 \mathrm{~N}, 29$ Canis Majoris, the nucleus of NGC 2392 , the nucleus of IC 4I8, HD I92639, HD ro8, and several southern stars.

To supplement the descriptions given by C. H. Payne ${ }^{39}$ of spectra of southern stars of a similar type, we shall give here some additional data on two $\mathrm{O}$ stars situated in the cluster NGC 623I, i.e., HD I 5 I804 and HD I 52408.

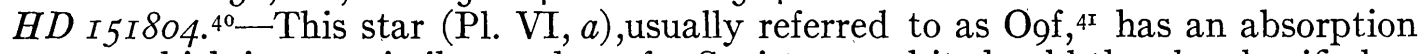
spectrum which is very similar to that of 9 Sagittae, and it should thus be classified as $\mathrm{O}_{7}$ f. Emission is observed in the following lines: $H a$ and $H \beta$ (the latter with violet absorption); $H e$ I 5876; He II 4686; $N$ III 4634 and 464I; $C$ III 5696. As in 9 Sagittae, $N$ III 4097 and 4IO3 are present only as strong absorptions; an unidentified line measured at $\lambda 4485$ is also present in 9 Sagittae. The peculiar selectivities observed among the $N$ III lines in the shell of 9 Sagittae are also observed in HD I 5I804. The $C$ III line has about the same intensity as $N$ III 4640, so that the relative intensities of $C$ III and $N$ III in the present star are intermediate between those in 9 Sagittae ( $N$ III strong, $C$ III weak) and HD I92639 ( $C$ III strong, $N$ III weak [Pl. VI, $c]$ ).

$H D I 52408.42$ - As in 9 Sagittae, all the lines of the Pickering series of $H e$ II are observed in pure absorption; they are seen clearly to $\lambda 3769.3(n=22)$ and certainly belong to the underlying star (Pl. VI, $b$ ). On the contrary, the strong emission at $\lambda_{4} 686$ belongs to an outer shell. The Balmer lines are observed in emission to $H \epsilon$, the line $H a$ being about of the same intensity as $\mathrm{D}_{3}$; no part is being played in the Balmer emission by $H e \mathrm{II}$, since $\lambda 454 \mathrm{I}$ and $\lambda 5_{54} \mathrm{I} 2$ of $H e \mathrm{II}$ are present in pure absorption. Many $H e \mathrm{I}$ lines have both an emission and an absorption component (i.e., $\lambda \lambda{ }_{5876}, 4026$, 4I 2I , 447I). Five lines of $N$ III are observed in the shell (emission and violet absorption), but our spectrograms do not show any trace of $N$ IV. $C$ III 5696 is an emission of intensity $(4 E)$, comparable to the lines $\lambda \lambda{ }_{4097}(4 E), 4 \mathrm{IO} 3(4 E)$, and $4634(5 E)$ of $N$ III. ${ }^{43}$ An unidentified line, which was also present in 9 Sagittae, was measured near $\lambda 45 \circ 3$ ( $\mathrm{A}$, I $E$ ). The width of the "nuclear" line $\lambda 4542$ ( $5 \mathrm{~A}$ ) is $6.13 \mathrm{~A}$ or $405 \mathrm{~km} / \mathrm{sec}$. For future discussions, it is useful to tabulate the widths and displacements of a number of lines of the shell. These are given in Table 4.

Some characteristics of the shells in Of stars.--Striking variations have been observed recently in the spectrum of the Of star HD I08.44 Less conspicuous variations have taken place in 9 Sagittae, $\mathrm{BD}+35^{\circ} 3930 N$, $\mathrm{HD} 34656$, and $\mathrm{HD}$ I90864. This is probably true also for some of the southern stars previously described by C. H. Payne but for which recent McDonald spectrograms differ appreciably from Miss Payne's description. These variations concern only the outer shells which give rise to emission and displaced absorption lines, and they emphasize the temporary character of certain of these shells.

Previous investigations of Of stars have emphasized the strong selection shown by the emission and absorption lines in the shells of 9 Sagittae, ${ }^{45} \mathrm{BD}+35^{\circ} 3930 \mathrm{~N},{ }^{45} \mathrm{HD}$ I $92639,4^{6}$ the nucleus of IC $4 \mathrm{I} 8,47$ and some other peculiar stars. This selection is summarized in Table 5 .

It appears at once that this selection has no connection either with the metastability of certain spectral terms or with the excitation potential. A similar, yet unexplained,

39. Harvard Bull., Nos. 842, 843, 878, г927; Zs.f. Ap., 7, r, r933.

$4^{\circ} \mathrm{CD}-4 \mathrm{I}^{\circ} \mathrm{I0957} ; m_{v}=5.4 ; \alpha(\mathrm{I} 900)=\mathrm{I}^{\mathrm{h}} 44^{\mathrm{m}} \cdot 5 ; \delta(\mathrm{I} 900)=-4 \mathrm{I}^{\circ} \circ 4^{\prime}$.

${ }_{4 \mathrm{I}}$ The suffix $f$ used by the Victoria observers refers to the emission at $\lambda \lambda{ }_{4} 634,4640$, and 4686.

${ }^{2} \mathrm{CD}-40^{\circ}$ Io919; $m=6.03 ; a(\mathrm{r} 900)=\mathrm{I} 6^{\mathrm{h}} 48^{\mathrm{m}} \cdot 0 ; \delta(\mathrm{r} 900)=-4 \mathrm{I}^{\circ} 00^{\prime}$.

43 The observation of $C$ III in HD I 5 r 804 and HD I $_{5} 2408$ is in disagreement with the inclusion of these stars by C. H. Payne in a group of stars without carbon (Zs.f. Ap., 7, r, 1933).
44 Pub. A.S.P., 53, 35, т941.
${ }_{46}^{6}$ Pub. A.S.P., 52, 394, I940.
${ }_{45} A p . J .$, 9г, 569, I940.
47 Proc. Nat. Acad., 27, 225, I94I. 
WOLF-RAYET STARS

TABLE 4

SHELL OF HD I 52408

\begin{tabular}{|c|c|c|c|c|c|c|c|c|}
\hline \multirow{2}{*}{ ELEMENT } & \multirow{2}{*}{$\begin{array}{l}\text { WAVE } \\
\text { LENGTH }\end{array}$} & \multicolumn{3}{|c|}{ ABSORPTION } & \multicolumn{3}{|c|}{ EMrssion } & \multirow{2}{*}{$\begin{array}{c}\text { DISTANCE BE- } \\
\text { TWEEN CENTERS } \\
\text { OF ABSORPTION } \\
\text { AND EMISSION } \\
\text { COMPONENTS } \\
\text { (IN KM/SEC) }\end{array}$} \\
\hline & & Intensity & $\begin{array}{l}\text { Width } \\
\text { in A }\end{array}$ & $\begin{array}{l}\text { Width in } \\
\mathrm{Km} / \mathrm{Sec}\end{array}$ & Intensity & $\begin{array}{l}\text { Width } \\
\text { in A }\end{array}$ & $\begin{array}{l}\text { Width in } \\
\mathrm{Km} / \mathrm{Sec}\end{array}$ & \\
\hline$H \ldots \ldots \ldots$ & $H_{\gamma}$ & 2 & 2.95 & 204 & 3 & 2.07 & I 43 & 208 \\
\hline \multirow[t]{3}{*}{$H e \mathrm{I} \ldots}$. & 4026.2 & 2 & 2.73 & 203 & I & 2.17 & I62 & I 7 I \\
\hline & $4 \mathrm{I} 20.8 \mathrm{I}$ & $O-I$ & & $\ldots \ldots \ldots$ & o & $\ldots \ldots$ & $\ldots \ldots$ & I 53 \\
\hline & 447 I. 48 & 3 & 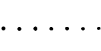 & . & 3 & $\ldots \ldots$ & $\ldots$ & 202 \\
\hline$H e \mathrm{Ir} . .$. & $4865.8 \mathrm{I}$ & I & 4.18 & 267 & Io & $4 \cdot 75$ & 304 & 290 \\
\hline \multirow[t]{5}{*}{$N$ iñ.... } & $4097 \cdot 3 \mathrm{I}$ & 5 & $3 \cdot 33$ & 244 & 4 & $3 \cdot 24$ & 237 & 233 \\
\hline & $4103 \cdot 37$ & 5 & $3 \cdot 30$ & $24 \mathrm{I}$ & 4 & $3 \cdot 49$ & 255 & 228 \\
\hline & $4634 \cdot 16$ & \multicolumn{2}{|c|}{ No abs. } & & 5 & $3 \cdot 99$ & $25^{8}$ & $\ldots \ldots$ \\
\hline & 4640.64 & \multicolumn{2}{|c|}{ No abs. } & & 6 & $3 \cdot 79$ & 245 & $\cdots \cdots$ \\
\hline & $4379 \cdot I$ & I & & & 0 & $\ldots$ & $\ldots \ldots$ & $\ldots \ldots \ldots \ldots$ \\
\hline \multirow[t]{2}{*}{$S i$ IV.... } & 4088.86 & 2 & 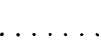 & . & 2 & & & I66 \\
\hline & $4 \mathrm{II} 6.10$ & I & & & 3 & $2.9 \mathrm{I}$ & 212 & I79 \\
\hline
\end{tabular}

TABLE 5

EMISSION LINES OBSERVED IN THE SHELL OF Of STARS

\begin{tabular}{|c|c|c|c|}
\hline Element & Wave Lengths & Notations & $\begin{array}{l}\text { Term Values } \\
\text { (in Volts) }\end{array}$ \\
\hline$N$ пाI......... & $4634 \cdot 2-4640.6$ & $3 \mathrm{p}^{2} \mathrm{P}^{0}-3 \mathrm{~d}^{2} \mathrm{D}$ & $30 \cdot 3-33.0$ \\
\hline$N$ IV $\ldots \ldots \ldots$ & 4057.8 & $3 \mathrm{P}^{\mathrm{I}} \mathrm{P}^{0}-3 \mathrm{~d}^{\mathrm{I}} \mathrm{D}$ & $49 \cdot 9-53 \cdot 0$ \\
\hline$N$ v........... & $4603-46 I_{9}$ & $3 \mathrm{~s}^{2} \mathrm{~S}-3 \mathrm{P}^{2} \mathrm{P}^{0}$ & $56 \cdot 3-59 \cdot 0$ \\
\hline$C$ III... & $5^{696}$ & $3 \mathrm{P}^{\mathrm{x}} \mathrm{P}^{0}-3 \mathrm{~d}^{\mathrm{x}} \mathrm{D}$ & $32.0-34 \cdot x$ \\
\hline$S i \mathrm{IV} \ldots$ & $4089-4 \operatorname{II} 6$ & $4 \mathrm{~S}^{2} \mathrm{~S}-4 \mathrm{p}^{2} \mathrm{P}^{0}$ & $24.0-27.0$ \\
\hline$H \alpha, H \beta \ldots$ & $6563-486 I$ & $2 \mathrm{p}^{2} \mathrm{P}^{0}-3,4 \mathrm{~d}^{2} \mathrm{D}$ & $\begin{array}{r}\text { I0. } 2-\text { I } 2.0 \\
(\text { I } 2.7)\end{array}$ \\
\hline$H e \mathrm{I}$. & $5^{876}$ & $2 \mathrm{p}^{3} \mathrm{P}^{0}-3^{3} \mathrm{D}$ & $20 \cdot 9^{-23} \cdot 0$ \\
\hline He ᄑ. & 4686 & $3 \mathrm{~d}^{2} \mathrm{D}-{ }_{4} \mathrm{f}^{2} \mathrm{~F}^{0}$ & $48.2-50.8$ \\
\hline
\end{tabular}


selection is also well apparent in P Cygni stars, which represent a stage of excitation lower than the Of objects. For example, in P Cygni all the observed transitions of $S i$ III, for which the terms $4 \mathrm{p}^{\mathrm{x}} \mathrm{P}^{0}$ or $4 \mathrm{p}^{3} \mathrm{P}^{0}$ are the upper level, are present in absorption; whereas those transitions for which these terms $4 \mathrm{p}^{\mathrm{I}, 3} \mathrm{P}^{0}$ are the lower level are in emission. $4^{8}$

The selection is present in the spectrum of $\mathrm{HD} \mathrm{I}_{5} \mathrm{I} 804$, but it has almost disappeared in $\mathrm{HD}$ I 52408 . In this latter Of star, the emission is much more pronounced than in 9 Sagittae, HD I 51804, and other Of's considered before. For example, $\lambda_{4097}$ and $\lambda$ 4IO3 of $N$ III appear in the shell, together with $\lambda_{4634}$ and $\lambda{ }_{464}$ I of $N$ III. This observation shows that in the Of stars the selection decreases when the emission and absorption in the shell increase. It has actually disappeared in Wolf-Rayet atmospheres.

The temperature of the underlying star in 9 Sagittae and other $\mathrm{O}_{7} \mathrm{f}$ objects is approximately $40,000^{\circ}$. This value may be obtained, for example, by considering that the strongest observed absorption lines of $N$ IV and $N$ III have about the same intensity, despite a difference of excitation of about 20 volts. The mean electron density in the reversing layer of the underlying star may be readily estimated by determining the quantum number $n$ of the line where the Pickering series terminates; in 9 Sagittae and HD $152408, n=22$. Inglis and Teller ${ }^{49}$ in their investigation of the termination of spectral series, brought about by static Stark effect due to charged particles, obtained the following formula:

$$
N=0.027 \times a_{0}^{-3} \times n^{-15 / 2}
$$

where $a_{0}$ is the Bohr radius and $N$ the density of positive ions. For $n=22$ (underlying star),

$$
N=\mathrm{I} .55 \times \mathrm{IO}^{\mathrm{I} 3} \text { per } \mathrm{cm}^{3}
$$

The absence of any strong dilution effect in an Of shell shows that the dilution factor is not small (see sec. III). The electron density in the shell must be lower than $1.5 \times 10^{13}$. For further calculations of ionization, let us adopt for the shell a dilution factor 0.2 and an electron density $N_{e}=\mathrm{I} .5 \times \mathrm{IO}^{\mathrm{I3}}$ per $\mathrm{cm}^{3}$. In these conditions $H e$ is almost completely in the doubly ionized state $H e^{++}, N^{+}$is practically nonexistent, $N^{+H}$ is more abundant than $N^{++}$(by a factor of the order of 100),,50 and $N^{+1++}$ is somewhat less abundant than $N^{+++}$. Similarly, $C^{+++}$is much more abundant than $C^{++}$, and this in turn is more abundant than $C^{+}$.

Under these conditions it seems difficult to escape the conclusion that the emission lines observed in the shells arise in the capture of electrons by ions. It is difficult to understand how collisional excitations could be sufficiently efficient. For example, if the stellar temperature is $40,000^{\circ}$, we may, as a working hypothesis, adopt an electron temperature of about $34, \infty 0^{\circ}$. Under such conditions only a very small percentage of the number of electrons (less than 0.3 per cent) would have energies higher than 33 volts, required to excite the $N^{++}$atoms. As, on the other hand, nitrogen is mostly in the trebly ionized state, the excitation of $N$ Im lines by collisions of $N^{++}$ions with electrons of high kinetic energy has a very small probability. It is thus likely that the emission is due to a recombination of ions and electrons, which under the physical conditions of the Of shells takes place according to definite selections. These selections disappear in the Wolf-Rayet envelopes characterized by much more powerful emission compared with absorption and by the disappearance of the spectrum of the underlying star.

${ }^{8}$ Pub. A.S.P., 52, 394, 1940.

49 Ap. J., 90, 439, 1939.

${ }^{50}$ This was the basis for our estimation of the stellar temperature. 
An electron density of $10^{13}$ or even one lowered by a factor of $10^{3}$ or $10^{4}$ is much too high to permit forbidden lines to appear with any appreciable intensity in an Of shell. Similar results may be obtained for pure Wolf-Rayet stars, which never show forbidden lines unless they are surrounded by a nebula.

In the case of the outer shell of $\gamma$ Cas, which grew steadily weaker in I940 and I94I, it has been shown that the optical thickness for continuous radiation of the shell near its maximum development was about $\tau_{\mathrm{I}}=0.2 .^{5 \mathrm{I}}$ If the Of shells have opacities of the same order of magnitude - which is likely, considering the intensities of the emission lines of $H, H e$ II, $N$ III, and $C$ III-we should expect a difference between the opacities of the

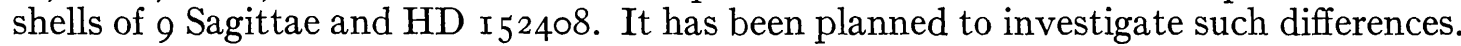

\section{SOME GENERAL GEOMETRICAL AND PHYSICAL PROPERTIES OF WOLF-RAYET STARS AND RELATED OBJECTS}

Dimensions of the shell.-It has often been assumed that the radius of a Wolf-Rayet envelope is large compared with the radius of the photospheric surface. This picture was mostly based on the fact that no appreciable occultation effect has been observed in the profiles of the Wolf-Rayet emission lines. Against such a picture, Chandrasekhar, in I934, wrote the following: "Any dynamical theory for the ejection of the atoms would not provide stellar atmospheres so extensive as to justify our regarding the parent star as of negligible dimensions." ${ }^{2}$ Consequently, Chandrasekhar computed the effect of an occultation in a line profile.

Despite the failure to observe an occultation effect, several types of evidence, besides the absence of forbidden lines, lead to the result that the radius $R$ of the shell is not much larger than the radius of the photosphere, say, in any case, not larger than ${ }_{5}^{r}$ (probably less).

I. The violet-displaced absorption components observed in Wolf-Rayet spectra do not show any appreciable dilution effect. The best criteria for dilution in Wolf-Rayet atmospheres are the following $\mathrm{He}$ I lines:

$$
\begin{aligned}
& { }_{2 \mathrm{~S}^{3} \mathrm{~S}}-\mathrm{np}^{3} \mathrm{P}^{0} \ldots \ldots\left(\lambda_{3889}\right)
\end{aligned}
$$

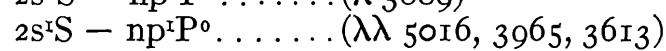

$$
\begin{aligned}
& 2 \mathrm{p}^{3} \mathrm{P}^{0}-\mathrm{nd}^{3} \mathrm{D} \ldots \ldots\left(\lambda_{5876}, 447 \mathrm{I}, 4026\right) \\
& 2 \mathrm{p}^{\mathrm{I}} \mathrm{P}^{\mathrm{o}}-\mathrm{nd}^{\mathrm{I}} \mathrm{D} \ldots \ldots\left(\lambda \lambda 6678,49^{22}, 4388,4 \mathrm{I} 44\right)
\end{aligned}
$$

The lines having the lower level $2 \mathrm{~S}^{3} \mathrm{~S}$ or $2 \mathrm{~S}^{\mathrm{I}} \mathrm{S}$ (metastable states) are enhanced in a diluted atmosphere, compared to those having the lower level $2 \mathrm{p}^{3} \mathrm{P}^{0}$ and $2 \mathrm{p}^{\mathrm{x}} \mathrm{P}^{0}$. As is evidenced by Struve and Wurm's calculations, ${ }^{53}$ the dilution effect decreases with increasing temperature..$^{54}$ Yet at a temperature of $25,000^{\circ}$ the easily observable lines $\lambda \lambda 3889,5016$, and 3965 are enhanced three times compared to $\lambda \lambda{ }_{5876}, 447 \mathrm{I}$, and 4026 when we pass from $W=$ I to $W=$ o.I ( $W=$ dilution factor). Even at temperatures as high as $75,000^{\circ}$, it does not seem possible to accept a dilution $W \leqslant 0.0$ I for the average position of the absorbing layer. Further quantitative photometric investigations are planned in this direction.

2. Let us consider the case of a pure phenomenon of ejection and assume that the width of the violet-absorption component is mostly due to the range in the component of the ejection along the line of sight, inside the star's cylinder of sight. We may then very easily determine the mean distance of the absorbing layer. This will give only a minimum value of $R$, since other causes of broadening may exist, but the order of magnitude will probably be correct. Such a procedure was followed previously by O. C. Wilson

${ }^{51} A p . J .$, 94, 29I, I94I.

${ }^{52} M . N ., 94,522$, I934.

53 Ap. $J ., 88,84$, I938, Table 4.

$54 \mathrm{Mr}$. P. Ledoux has kindly computed the dilution effects for $T=75,000^{\circ}$ and has found that for $W=0.1, \lambda_{5876}$ will still be reduced by a factor of 2 compared to $\lambda_{3888}$. 
for three Wolf-Rayet stars ${ }^{55}$ and by Struve and Swings for 9 Sagittae. ${ }^{66}$ If $V$ is the ejection velocity and $\Delta V$ the width of the absorption line, a first approximation will be b $^{57}$

$$
R_{\text {shell }}=r_{\text {nucleus }} \times \sqrt{\frac{V}{2 \Delta V}} .
$$

Applying this formula to $\mathrm{HD} \mathrm{I}_{2} \mathrm{I}_{6}\left(\mathrm{WC}_{7}\right), \mathrm{O}$. C. Wilson gets $R=1.9 r$; for two other stars he obtains $R=\mathrm{I} .4 r$ and 2.I $r$. We shall see farther on that our values are slightly smaller than these.

The application of formula ( $\mathrm{I}$ ) may lead to the right order of magnitude in certain cases of Wolf-Rayet stars where the lines are very broad and where the essential process is assumed to be the continuous ejection of high-speed atoms from the stellar surface. It becomes much less reliable when the lines become sharper, such as in the Of stars, where rotation and turbulence may play an important part in the broadening of the line. The determination of $R$ must proceed by successive approximations. The value of the ejection velocity may not be obtained so easily from the profiles of the emission and the absorption components. On the red side of the emission the profile is being reduced by the occultation effect, and this must be compensated by some reduction not yet accounted for in the violet part of the emission. Considering the complexity of the interpretation of profiles, it appears best to find a first approximation of $R$ by taking for $V$ half of the distance from the red end of the emission to the blue end of the absorption. In a second approximation, $V$ may be corrected for the occultation effect.

The first approximation is equivalent to

$$
R=\frac{r}{2} \sqrt{\frac{\Delta_{t}}{\Delta_{a}}},
$$

$\Delta_{t}$ and $\Delta_{a}$ being respectively the total width and the width of the absorption line. Applying formula (2) to our spectrograms and using various well-defined lines, we obtain

$$
\begin{aligned}
& \text { for HD } 192 \mathrm{r} 63 \ldots \ldots \ldots R=\mathrm{r} .25^{r} \text { (Wilson found } R=\mathrm{I} .9^{r} \text { ) } \\
& \text { for HD I64270........ } \\
& \text { for } \mathrm{BD}_{3} 0^{\circ} 3639 \ldots \ldots . R=\mathrm{I} .28 r
\end{aligned}
$$

A second approximation, taking into account the occultation effect, would give values of $R$ about Io or I 5 per cent larger. On the whole, a value $R={ }_{1.4} r$ or I. $5 r$ appears to be of the right order of magnitude. A similar value or slightly larger $(2 r)$ would be found for 9 Sagittae. The dilution factor corresponding to $R=I_{.5} r$ is $W=0$. II. At a temperature of the order of $50,000^{\circ}$ such a dilution factor has no conspicuous effect on the relative intensities of characteristic lines, whereas it would already be important in a star of lower excitation, like P Cygni. Besides the technical difficulties, the limitations of the method are obvious and appear very strikingly when we try to apply formula (2) to certain stars, such as HD I 52408, which would give a value of $R$ equal to or smaller than $r$. This simply means that the other causes of broadening (rotation, turbulence, range in ejection velocity within the absorbing layer) are not negligible in such cases. For very broad lines (as in HD I92163), the main objection to the method is obviously that it neglects the range in ejection velocity within the layer giving rise to absorption lines. But the neutral $\mathrm{He}$ atoms exist only in the very outer parts of the Wolf-Rayet shells and a variation of about 30 per cent of the ejection velocity of $H e \mathrm{I}$ in this probably

$$
\begin{aligned}
& { }^{55} \mathrm{~A} \text { p. J., 91, 403, I940. } \\
& { }^{56} \mathrm{Ap} . J ., \text { 9 1, 566, I940. }
\end{aligned}
$$

${ }^{57}$ Neglecting $(\Delta V / V)^{2}$ compared to $2 \Delta V / V$. 
thin layer appears rather unlikely. The method is evidently too crude to provide evidence in favor of the stratification of elements, which is strongly suggested by various other observations.

The essential result of this discussion is the relatively small size of the Wolf-Rayet shells compared to the photospheric surfaces. A value $R={ }^{1} \cdot 5^{r}$ seems to be a good approximation, and it does not appear logical to accept values exceeding $5 r$ (which would give $W=0.01$ ). This is similar to the result of the discussion by $\mathrm{O}$. C. Wilson.

Line profiles.-Despite the numerous theoretical and observational investigations of line profiles in Wolf-Rayet stars,,$^{8}$ the question is far from solved. The violet edge of the emission lines, which have an absorption component, is usually sharper than the red edge, as it appears in HD I64270 on Plate V, c. This may be easily understood by combining a smooth symmetrical emission profile with a continuous background cut by an absorption line which sets in at a distance from the center equal to $V_{\mathrm{ej}} \sqrt{\mathrm{I}-(r / R)^{2}}$. This absorption should begin and end rather abruptly, if the ejection velocity does not vary much in the absorbing layer.

Obviously, this is only a crude treatment of the problem. It neglects any darkening toward the limb and any occultation effect. Moreover, the simple addition of a lineemission profile and of a background depleted by an absorption line is only a rough approximation to a problem which should require the solution of the equation of transfer corresponding to the present case.

But two main points which require special attention at present are the occultation effect and the central reversals. If we adopt, for example, $R=\mathrm{I} .45 r, 28$ per cent of the red wing must be lost. How is it that the lines do not show any definite asymmetry or any very peculiar radial velocities? The absorption line displaced to the violet and affecting the background is not always present and therefore could not explain all cases. There is no escaping the conclusion that in the violet part of the emission lines some reabsorption process compensates approximately for the occultation ${ }^{59}$ if $R$ is not larger than $3^{r}$. On the other hand, if we adopt $R=5^{r}$, only 2 per cent of the red wing is lost by obscuration, which would be unobservable. Actually, the obscuration effect may be different for different stages of ionization of the same atom.

Central reversals are rarely observed in Wolf-Rayet stars but are well apparent in many lines of $H D{ }_{5} 2270$. These central absorption lines are undisplaced, and it seems highly improbable that they are absorption lines belonging to some other star. ${ }^{60}$ In HD I 52270 , microphotometer tracings of $H \beta$, which has a width of $54.9 \mathrm{~A}$ (or 3387 $\mathrm{km} / \mathrm{sec}$ ), give for the central absorption a width of $\mathrm{I} 7.25 \mathrm{~A}$ (or $1064 \mathrm{~km} / \mathrm{sec}$ ). According to C. H. Payne, ${ }^{6}$ the central absorptions have been regarded by Gerasimovič as "confirming the idea that the bright lines are formed at low levels in the atmosphere, and are broadened by pressure." This hypothesis is hardly tenable now. Rosseland has given another interpretation. ${ }^{62}$ The reabsorption effect would occur preferentially near the

$5^{8}$ Beals, Pub. Dom. Ap. Obs., 6, I I r, I934; Gerasimovic, Zs. f. Ap., 7, 335, I933; Chandrasekhar, loc. cit.; O. C. Wilson, Ap.J., 80, 259, I934; Araki and Kurihara, Zs.f.Ap., r3, 89, I936.

59 The asymmetry would be removed if we assume that the atoms, after ascending to a certain distance, begin to fall back toward the photosphere; we have, moreover, to assume that these descending atoms are equally efficient in contributing to the emission. But then how could we explain the violet absorption? This matter was discussed by Chandrasekhar (loc. cit.), who concluded that it is best to neglect the emission by descending atoms.

60 They cannot be attributed to a stationary shell, since this latter would not show any trace of dilution (reversal in $\mathrm{He}$ I $447 \mathrm{I}$ as strong as in $\mathrm{He} \mathrm{I} 5 \mathrm{Or} 6$ ) and would have to lie very near the region of line emission. Beals's suggestion (Pub. Dom. Ap. Obs., 4, 295, I929) to attribute the absorption lines to the underlying star does not appear very probable, since we should assume that the ionization of the nucleus should be higher than in the shell. On the contrary, the central absorption is very pronounced in the Balmer lines, which would require a high percentage of neutral hydrogen in the underlying star.

${ }^{6 r}$ Harvard Bull., No. 874 , p. 25, I930.

${ }^{62}$ Theoretical Astrophysics, p. 294, Oxford, r936. 
center of the line, where the line of sight passes the luminous shells tangentially and the optical paths in the shell are a maximum. It is easily seen that the reversal may not take place when the envelope is uniformly accelerated outward, but it may take place when the outward motion of the atmosphere is uniformly decelerated. If further investigation proves the correctness of Rosseland's suggestion, the central reversals will bring the first clear evidence regarding the deceleration or acceleration of specific ejected atoms.

Araki and Kurihara ${ }^{6}$ have investigated theoretically the effect of absorption upon the band profiles in expanding shells and their work shows conclusively how wide a variety of profiles may be obtained, including some with a minimum in the center. But no satisfactory general conclusions appear possible yet from a comparison of their theoretical profiles to the observed ones.

Chemical constitution of the ejected layers.-There is no doubt that certain WolfRayet stars show only carbon, the best example being the nucleus of Campbell's envelope star. It is quite certain also that in certain W stars, the nitrogen lines are much stronger than the carbon lines. But we have now also conclusive evidence that there are intermediate objects, showing simultaneously carbon and nitrogen with various intensity ratios.

In the typical WN6 star, HD I92 63 , the line $\lambda{ }_{580} 8$ is in all likelihood due to $C$ IV and not to $N$ IV, as was shown in section I. Our investigation of the nucleus of NGC 6543 has shown that $C$ IV and $N$ IV have similar intensities. The description of the nuclear spectrum of NGC 6572 by Wright ${ }^{64}$ shows that the characteristic lines $\lambda 4634$ and $\lambda{ }_{464} \mathrm{I}$ of $N$ III, $\lambda{ }_{4650}$ of $C$ III, $\lambda \lambda_{4659}, 5802$, and 58 I 2 of $C$ IV are present. There is also definite evidence of the simultaneous presence of $C$ and $N$ with similar intensities in the Wolf-Rayet nucleus of NGC 6826 . We have observed the characteristic lines of $N$ III and $C$ III with similar intensities in the nucleus of IC 4997. In the nucleus of IC ${ }_{41} 8$ we observed very strong bright lines of $N$ III $\left(\lambda\right.$ 4634.I 6 and $\lambda 4_{4640.64)}, C \operatorname{III}\left(\lambda \lambda{ }_{4647.40}\right.$, $4650.16-465 \mathrm{I} .35,4665.90,5696,4325)$, and weaker lines of $C$ II $\left(\lambda 4_{267}\right)$ and $N$ IV $(\lambda$ 4058). This nucleus constitutes an intermediate between the 9 Sagittae type and the pure Wolf-Rayet type stars, the emission being much stronger than in 9 Sagittae, but undisplaced absorption lines of $\mathrm{He}$ II (Pickering series only, $\lambda_{4} 686$ being bright) are still present.

Variations in the relative intensities of the emission lines of $N$ and $C$ are also very striking in the Of stars. Typical examples are: (a) Of shells showing nitrogen lines, but no trace of carbon: $\mathrm{BD}+35^{\circ} 3930 \mathrm{~N}$, nucleus of NGC $239^{2}$, HD $15^{2} 386 ; 65(b)$ Of shells showing nitrogen lines and weaker carbon: 9 Sagittae, HD Io8 (in I94I); (c) Of shells showing $N$ III 464I and $C$ III 5686 of approximately the same intensity: HD I 5 I 804 , HD I $52408 ; 66$ and $(d)$ Of shells in which $C$ III 5686 is much stronger than $N$ III 464I: $\mathrm{HD}$ r 92639 .

It is interesting to consider also the shells of novae with regard to the relative abundance of $C$ and $N .{ }^{67}$ In the case of $\mathrm{N}$ Her, many lines of $C$ II, III, IV, and $N$ II, III, are still observed, whereas in the present spectrum of $\mathrm{N}$ Ser, the $N$ III lines are strong, but

${ }_{3}$ Loc. cit.

${ }^{6}$ Op. cit., p. 213.

${ }_{65}$ This interesting spectrum has been described by C. H. Payne (Harvard Bull., No. 842, I937) and by Seyfert and Popper ( $A p . J .$, 93, 46I, r94I). The latter authors mention the following bright lines: $H a, H \beta, H e$ II (4686), $N$ III $(4634,4640,4097), S i$ IV (4088 and 4II6). Our spectrograms reveal also bright $\mathrm{D}_{3}$ (He I 5876$)$ and a weak emission at $H e$ II 4542. C $\Pi$ is is absent.

${ }^{66}$ The nucleus of IC 4 I 8 may possibly be considered as belonging to this category.

${ }^{67}$ See the report of Swings at the Paris conference on novae and white dwarfs, r939. Some examples which seem to indicate peculiar abundances in nova shells are the tremendous intensity of $[F e$ vII] in Nova Pictoris I 925 , the strength of $[\mathrm{Ne}$ mI] in N Per and N Ser, of [ $F e m$ III in N Ser and in DO Aquilae r925; the absorption lines of $O \mathrm{I}$ and $C \mathrm{I}$ were especially strong in $\mathrm{N}$ Herculis. A lower abundance of hydrogen is not excluded in nova shells. 
there is no trace of carbon. ${ }^{68}$ In the spectrum of $Z$ Andromedae in August, r940, one year after the outburst of 1939 , the lines $N$ III 4634.2 and 4640.6 were of intensities similar to $C$ III 4647.4 and 4650.2 . The chemical constitution of the layers ejected in nova outbursts seems to differ from that of ordinary reversing layers, ${ }^{67}$ and the relative behavior of $C$ and $N$ should be investigated carefully.

The analysis of the spectrum of $\mathrm{P}$ Cygni has also shown ${ }^{69}$ that this post-nova is much more closely related to the nitrogen than to the carbon sequence. This is also true of $\mathrm{BD}+\mathrm{II}^{\circ} 4673$ and $\mathrm{CD}-27^{\circ} \mathrm{II} 944$, both of P Cygni type.

Classification of Wolf-Rayet spectra.-The classification suggested by Beals and adopted by the I.A.U. $7^{70}$ is based on the following criteria of excitation: $(a)$ in the WN stars: $N \mathrm{III} / H e \mathrm{II} ; N \mathrm{v} / H e \mathrm{II}$ and $H e \mathrm{I} / H e \mathrm{Ir}$; and $(b)$ in the WC stars: $C \mathrm{III} / C$ IV; $\mathrm{C} \mathrm{III} / \mathrm{O}$ v, $\mathrm{C} \mathrm{III} / \mathrm{He} \mathrm{II}, \mathrm{He} \mathrm{I} / \mathrm{He} \mathrm{II}$, and band widths.

Some additions or modifications may possibly appear advisable for the following reasons:

I. Certain objects contain both $C$ and $N$ and can obviously not be listed among the WC or among the WN stars.

2. Observational difficulties arise in the case of the planetary nuclei observable only with low dispersion. Fairly narrow nuclear lines have sometimes been observed: in this case the lines of $H, H e$ I, and $H e$ II (sometimes also $N$ III) may belong both to the nucleus and to the nebula, and it may be difficult to separate the two contributors.

3. We have noticed different relative abundances of carbon and nitrogen; it is not certain that the relative abundances of carbon and helium, or of nitrogen and helium, are constant for all Wolf-Rayet stars.

For these reasons, the following suggestions are tentatively made:

I. Continue to use the WN and WC notations whenever the predominance of $N$ or $C$ is definitely ascertained; in case of simultaneous presence of $N$ and $C$ with similar intensities, simply use the notation $\mathrm{W}$.

2. Devise criteria not involving $\mathrm{He} \mathrm{I}$ and $\mathrm{He} \mathrm{II}$ lines for the planetary nuclei, ${ }^{7 \mathrm{I}}$ in a way agreeing quantitatively with the presently adopted criteria.

3. Avoid comparisons between intensities of lines belonging to different elements and concentrate as much as possible on different stages of ionization of one element.

The application of these suggestions would require further photometric work and would probably be best performed under the auspices of the I.A.U.

The correlation of band width (of certain lines) and spectral type, especially in the carbon sequence, has often been emphasized. But here again great caution should be exercised in applying this excitation criterion, which holds only statistically. In some stars intermediate between Wolf-Rayet and Of stars, such as the nucleus of IC $4 \mathrm{I} 8$, which has strong emission lines of $N$ III, $C$ III, and $H e$ II, the lines have only a width of $I 55 \mathrm{~km} / \mathrm{sec}$, corresponding to an ejection velocity of the order of $80 \mathrm{~km} / \mathrm{sec}$. In $W$ stars of very early type, such as the nucleus of NGC 6543 , the two carbon lines

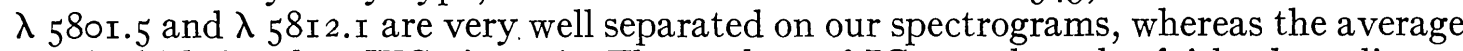
band width for class WC6 is $70 \mathrm{~A}$. The nucleus of IC 4997 has also fairly sharp lines.

${ }^{68}$ Because the fluorescence process of $N$ III excited by $H e$ II (via the $O$ III resonance line) has a great efficiency, the comparison between the intensities of $N$ and $C$ lines must be made carefully.

${ }^{69}$ Struve, Ap. J., 81, 66, r935.

70 Trans. I.A.U., 6, 250, 1938.

${ }^{71}$ It should be noted that the careful classification of the planetary nuclei is an important and urgent problem, especially in order to determine the temperatures of many nuclei, to discuss the excitation conditions in the nebulae, and to try to relate the chemical constitution of the nuclei to that of their surrounding nebulosities (e.g., it has been shown that several pure carbon nuclei are surrounded by a nebulosity which is very rich in nitrogen). 
At this stage a short comparison between Wolf-Rayet and P Cygni stars may be interesting. It is often assumed that the lines in P Cygni stars are narrower than in novae and in Wolf-Rayet stars, but there are many cases in which this assumption does not hold. For comparison, here are a few approximate values of the ejection velocities:

P CYGNI STARS

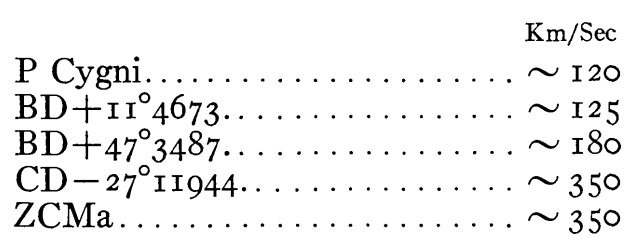

WOLF-RAYET STARS

$\mathrm{BD}_{3} 0^{\circ} 3639 \ldots \ldots \ldots \ldots \ldots \ldots \sim 300(\mathrm{He}$ II $)$

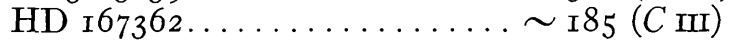

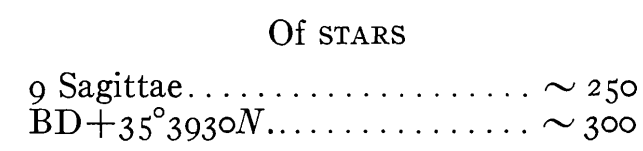

NOVAE

Very low velocities in $\mathrm{Z}$ And, $\mathrm{TCBr}$, RS Oph

The process of ejection of matter is essentially the same in Wolf-Rayet objects, P Cygni stars, Of stars, and novae. In all four cases there is a wide range in the velocity of ejection. An Of star differs from a Wolf-Rayet object in that the ejected layer is optically thin so that the spectrum of the underlying star itself may appear, although encountering continuous and line absorption in the shell; but for the essential properties (similar excitations, absence of forbidden lines) this thin layer is similar to a Wolf-Rayet envelope. The P Cygni stars have simply a lower excitation. The P Cygni shells may have widely different opacities, so that the underlying star may not be observed (as in P Cygni, CD $-27^{\circ}$ II944, and many novae) or may partly shine through (as in BD $+47^{\circ} 3487$, I 7 Leporis, HD I90073, and novae at certain stages)..$^{72}$ The P Cygni shells have a wider variety of dilution than the Wolf-Rayet stars; consequently, the dilution effects may be more pronounced in the P Cygni stars, ${ }^{73}$ and some of them present forbidden lines (e.g., $\mathrm{BD}+\mathrm{II}^{\circ} 4673, \mathrm{Z}$ CMa, RY Scuti, etc., and novae, e.g., in the $\lambda$ Carinae or RY Scuti stages).

Absolute magnitudes, temperatures, radii.-As is well known, there seems to exist a difference in absolute magnitude, of the order of three magnitudes, ${ }^{74}$ between the Wolf-Rayet stars and the planetary nuclei; and this is commonly considered as very strange, since it is usually assumed that there is no appreciable spectroscopic difference between Wolf-Rayet stars and planetary nuclei. That these nuclei have high temperatures has been established clearly by Wright, who emphasized the considerable extension of their continuous spectra into the ultraviolet and the occurrence of bright bands due to the same atoms as those identified in Wolf-Rayet stars. But a detailed examination of the spectra reveals that, except in rare cases, the spectra of planetary nuclei have not exactly the typical Wolf-Rayet type corresponding to their excitation. R. Minkowski

${ }^{72}$ All the dilution effects observed at certain stages of novae have their equivalent among the P Cygni, Of, or Wolf-Rayet stars.

73 As was mentioned before, the dilution effects on absorption lines are greater for lower temperatures.

74 Beals, J.R.A.S. Canada, 34, I79, I940. 
has found a very high ejection velocity in the nucleus of NGC $657 \mathrm{I}$, but this appears to be an exception. Here are some general indications concerning the best-known nuclei:

IC $4 \mathrm{r} 8 \ldots \ldots \ldots$ nucleus intermediate between $\mathrm{W}$ and $\mathrm{Of}$, contains $N$ and $C$

NGC $2392 \ldots \ldots \ldots \ldots$ nucleus of type Of

NGC $6543 \ldots \ldots \ldots \ldots$ nucleus containing $C$ and $N$; nuclear lines unusually sharp for observed excitation

NGC $6572 \ldots \ldots \ldots$ nucleus containing $C$ and $N$; lines $\lambda \lambda{ }_{4} 634,4641,4650,4568$ well separated; width of $\lambda 4686$ only I $5 \mathrm{~A}$

$\mathrm{BD}+30^{\circ} 3639 \ldots \ldots$. lines rather sharp (Pl. VII, $a$ )

NGC $6826 \ldots \ldots \ldots \ldots$ nucleus containing $C$ and $N$; width of $\lambda 4686$ only about $8 \mathrm{~A}$

IC $4997 \ldots \ldots \ldots \ldots$ nucleus containing $C$ and $N$; lines rather sharp

NGC $40 \ldots \ldots \ldots \ldots$ normal WC8 (Pl. VII, $b$ )

HD $167362 \ldots \ldots \ldots$ lines very sharp (Pl. VII, $c$ and $d$ )

On the whole, the planetary nuclei with emission lines seem to have lower ejection velocities than the $\mathrm{W}$ objects of similar excitation. Many nuclei have also a pure continuous spectrum. When we compare pure W stars and planetary nuclei, the smaller velocity of ejection would thus correspond to the objects of lower absolute magnitude. This is probably equivalent to lower surface gravity for the $\mathrm{W}$ stars, since the difference of radius would probably not be compensated by the difference of mass.

According to Sanford and Wilson 75 the mean absolute magnitudes of the Wolf-Rayet stars are: for WC (6 stars), - 2.8; for WN (I 2 stars), -2.I. From his data, Beals suggested a value of -2.0 to represent the intrinsic luminosity of the Wolf-Rayet stars as a class.

In sections I and II we have described the spectra of four stars in NGC 623I, the parallaxes of which are probably nearly identical. After correction for interstellar absorption,,$^{76}$ the absolute magnitudes obtained are as follows:

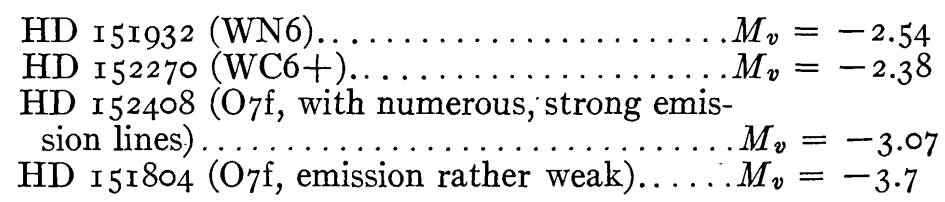

Even if the numerical values of the $M_{v}$ 's are in error, the differences should be correct. There is thus some indication that the Of stars are intrinsically brighter than the W objects. But such a comparison may have little meaning, since the temperatures and atmospheric structures of the W6 and $\mathrm{O}_{7} \mathrm{f}$ stars are so different.

In using the absolute magnitudes for determinations of radii or for similar calculations, the values adopted should refer only to the continuous background. In many cases the contribution of the emission lines to the visual or to the photographic magnitude may become very important. Before computing the photospheric radii in these cases, the magnitudes should be corrected, and this may be rather difficult and uncertain. For the stars in NGC 623I, the contribution of the line emission is small compared to the continuum, except for HD $5_{52270}$, in which a correction of a few tenths of a magnitude should be applied $\left(M_{\text {cont }} \sim-\right.$ I.8 or -2.0$)$. But the correction may amount to much more in many cases.

Assuming as a first approximation a black-body distribution for the continuous spectrum in the visual region, the following values of the radius are obtained:

HD I51932 (assuming $\left.M_{v}=-2.54, T=80,000^{\circ}\right) ; R=2.0 \odot$
HD I52270 (assuming $\left.M_{v}=-2.0, T=100,000^{\circ}\right) ; R=1.4 \odot$
HD I52408 (assuming $\left.M_{v}=-3.07, T=40,000^{\circ}\right) ; R=3.9 \odot$
(assuming $\left.M_{v}=-3.07, T=50,000^{\circ}\right) ; R=3.3 \odot$
HD I51804 (assuming $\left.M_{v}=-3.7, T=40,000^{\circ}\right) ; R=5.2 \odot$
$\quad\left(\right.$ assuming $\left.M_{v}=-3.7, T=50,000^{\circ}\right) ; R=4.5 \odot$

${ }^{75}$ Ap. J., 90, 235, 1939 .

${ }^{76}$ MacRae, op. cit. 
The values obtained for the $\mathrm{W}$ stars are similar to those obtained by Beals. ${ }^{77}$ The two Of stars have definitely larger radii.

The application of the theory of Zanstra to the determination of temperatures of $W$ olfRayet stars. - The temperatures adopted for $\mathrm{HD}$ I $5193^{2}$ and $\mathrm{HD} \mathrm{I}_{522} 20$ are the photoionization temperatures obtained by Beals by applying Zanstra's theory and by assuming that the photospheric surface radiates like a black body. It seems appropriate to make a few comments regarding this application, aside from the question of the applicability of black-body radiation.

a) The case of a nebula excited by a nucleus of Wolf-Rayet type.--Several years ago Bowen called attention to two important effects which might influence the photo-ioniza-

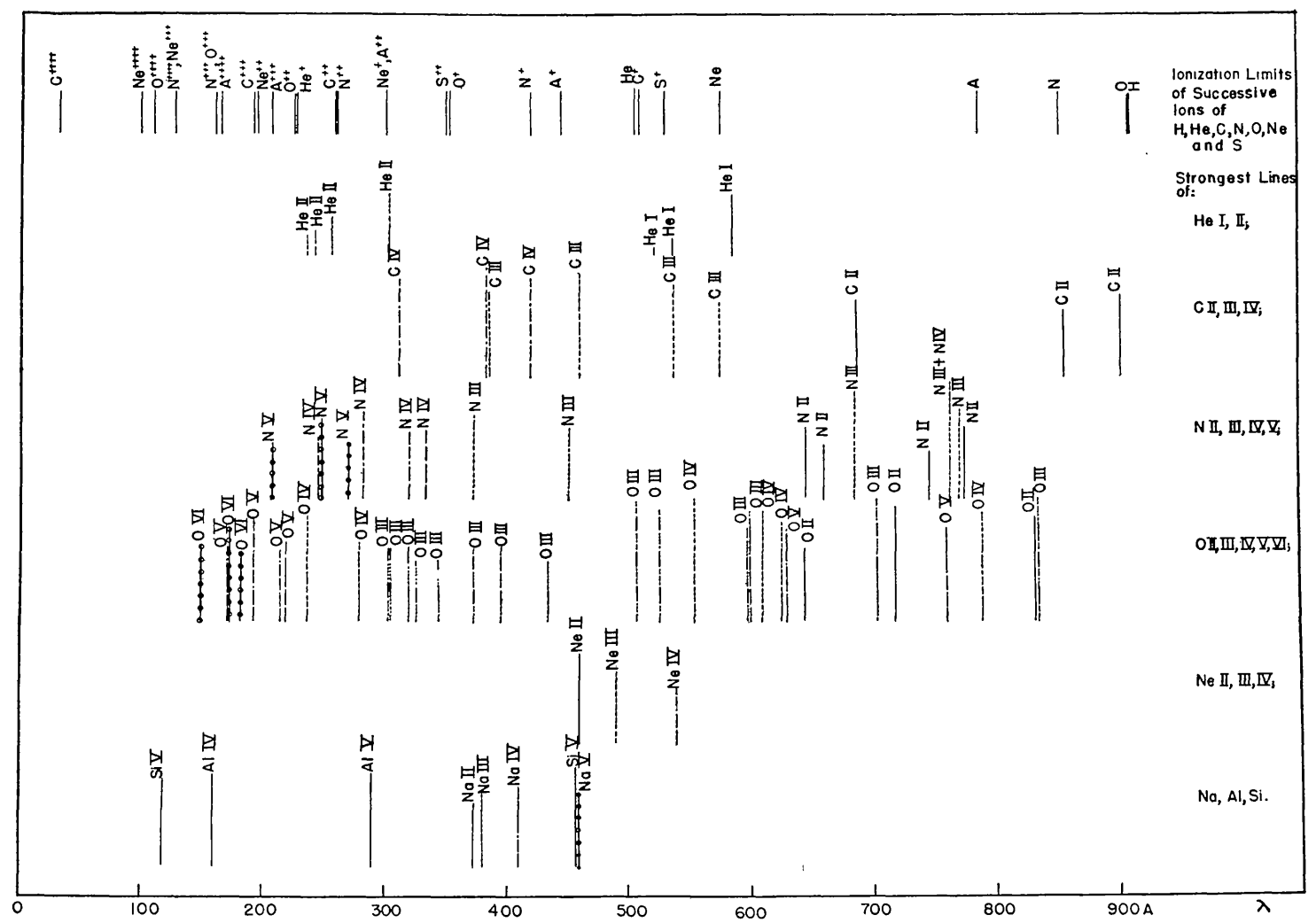

FIG. I.-Region $\lambda \lambda$ 30-9I $2 \mathrm{~A}$ in Wolf-Rayet stars

tion of certain atoms and, consequently, the intensity of the observable lines resulting from the recombination process. These are (I) the effect of the overlapping regions of photoelectric absorption and (2) the photo-ionization by the emission lines present in the extreme ultraviolet region of the spectrum of the nucleus and of the nebula.

To simplify the discussion of these effects, we have prepared a diagram (Fig. I), giving the ionization limits of the different abundant atoms or ions between $\lambda 30$ and $\lambda$ I $2 \mathrm{~A}$, together with the strongest lines of $\mathrm{He} \mathrm{I}, \mathrm{He} \mathrm{II}, \mathrm{C} \mathrm{II}-\mathrm{IV}, N \mathrm{II}-\mathrm{v}, O \mathrm{II}-\mathrm{VI}, N e \mathrm{II}-$ IV, $N a \mathrm{I}-\mathrm{v}, A l$ IV and v, Si IV and v. According to the spectral type of the Wolf-Rayet nucleus, it is easy to make a synthesis of the line emission most likely to be present. It should be noticed that the incomplete multiplets of $O$ III and $N$ III, which may be excited

77 In the binary $\mathrm{HD}$ r93576, the Wolf-Rayet component of type $\mathrm{WN}_{5}$ has a radius of $5.8 \odot$, according to S. Gaposchkin ( $A p . J ., 93,202$, I94I). Similarly, large radii would be obtained for HD I 5 I 932 and $\mathrm{HD}$ I 52270 by adopting a temperature of the order of $20,000^{\circ}$. 
by $\mathrm{He}$ II 304, are not enhanced in the Wolf-Rayet stars, as compared with the other transitions of $O$ III and $N$ III. Actually, $O$ III is always very weak or absent in the WN stars, and it does not show any selection in the WC stars. This seems to indicate that, in the Wolf-Rayet stars, practically all the intensity of the line emission is due to recombination and not to line excitation.

Applying this observation to the case of $H e$ II itself, we may infer that in W stars $H e$ II 304 does not build up a very high intensity at the expense of the higher members of the $\mathrm{IS}^{2} \mathrm{~S}-\mathrm{np}^{2} \mathrm{P}^{0}$ series $(\lambda \lambda 256.3 \mathrm{I}, 243.02,237.33)$, which may still retain an appreciable intensity when they leave the Wolf-Rayet star. For radial-velocity reasons, we may expect that only a minor part of the intensities of the lines $\lambda \lambda 256,243,237$ will be absorbed by the $\mathrm{He}$ II atoms in the nebula and by successive emissions will be transformed into $\lambda$ 304. Despite the fact that the absorption coefficient of line absorption is ordinarily greater than that for the photoelectric absorption below a series limit, a great part of the energy concentrated in the Wolf-Rayet lines $\lambda \lambda 256.31,243.02,237.33$, of $\mathrm{He}$ II will thus be used to ionize $\mathrm{C}^{++}$and $\mathrm{N}^{++}$.

On the other hand, the ionization of $\mathrm{O}^{++}$is not favored by these lines of $H e$ II. On the contrary, since $\mathrm{He}^{+}$and $\mathrm{O}^{++}$have almost the same ionization potential and since $\mathrm{He}^{+}$ is more abundant than $\mathrm{O}^{++}$, the ionization of $\mathrm{O}^{++}$may be slowed down.

This effect is observed in the nebula NGC $6543,,^{78}$ in which fairly strong permitted lines of $C$ III and $N$ III are present, but no permitted $O$ mI line. The general decrease of the continuous spectrum toward short wave lengths (about a factor of 2 between $\lambda 260$ and $\lambda$ 226) is not sufficient to explain the observed enhancement of $C$ III and $N$ III compared with $O$ III.

b) The case of the Wolf-Rayet star.-The stratified distribution of the elements which Bowen pointed out in the case of the nebulae ${ }^{79}$ is also present in the Wolf-Rayet envelope itself, as was shown especially by Beals. ${ }^{80}$ Hence the radiation which reaches a certain outer region of the $\mathrm{W}$ envelope has already suffered transformations in the deeper layers, part of the ultraviolet photospheric continuum having been absorbed photoelectrically and transformed into longer wave lengths. ${ }^{8 r}$ Thus photo-ionization by emission lines may become possible in the outer layers. Evidently the effect of overlapping regions of photoelectric absorption is the same inside the Wolf-Rayet envelope or in a nebula.

Other examples may easily be found in addition to the one concerning $\mathrm{He}^{+}, \mathrm{O}^{++}$, $N^{++}$, and $C^{++}$, for example, on the basis of the quasi-coincidence of the ionization potentials of neutral $H$ and $O$. It is quite certain that, even assuming a black-body photospheric radiation, the numerical values of the temperature obtained when applying Zanstra's theory may be different for different atoms.

In conclusion, I express my cordial gratitude to Dr. O. Struve for his interest in this work, his valuable suggestions, and his great help in securing the observational material.

YERKES OBSERVATORY AND

McDonald ObServatory August $\mathrm{x} 94 \mathrm{I}$

${ }^{78}$ Ap. J.,. 92, 289, 1940. ${ }^{79}$ Ap. J., 67, I, 1928.

${ }^{80}$ E.g., J.R.A.S. Canada, 34, 169, I940.

${ }^{8 x}$ Stratification is actually a general feature for all stellar envelopes, including shells of P Cygni and Be types. 


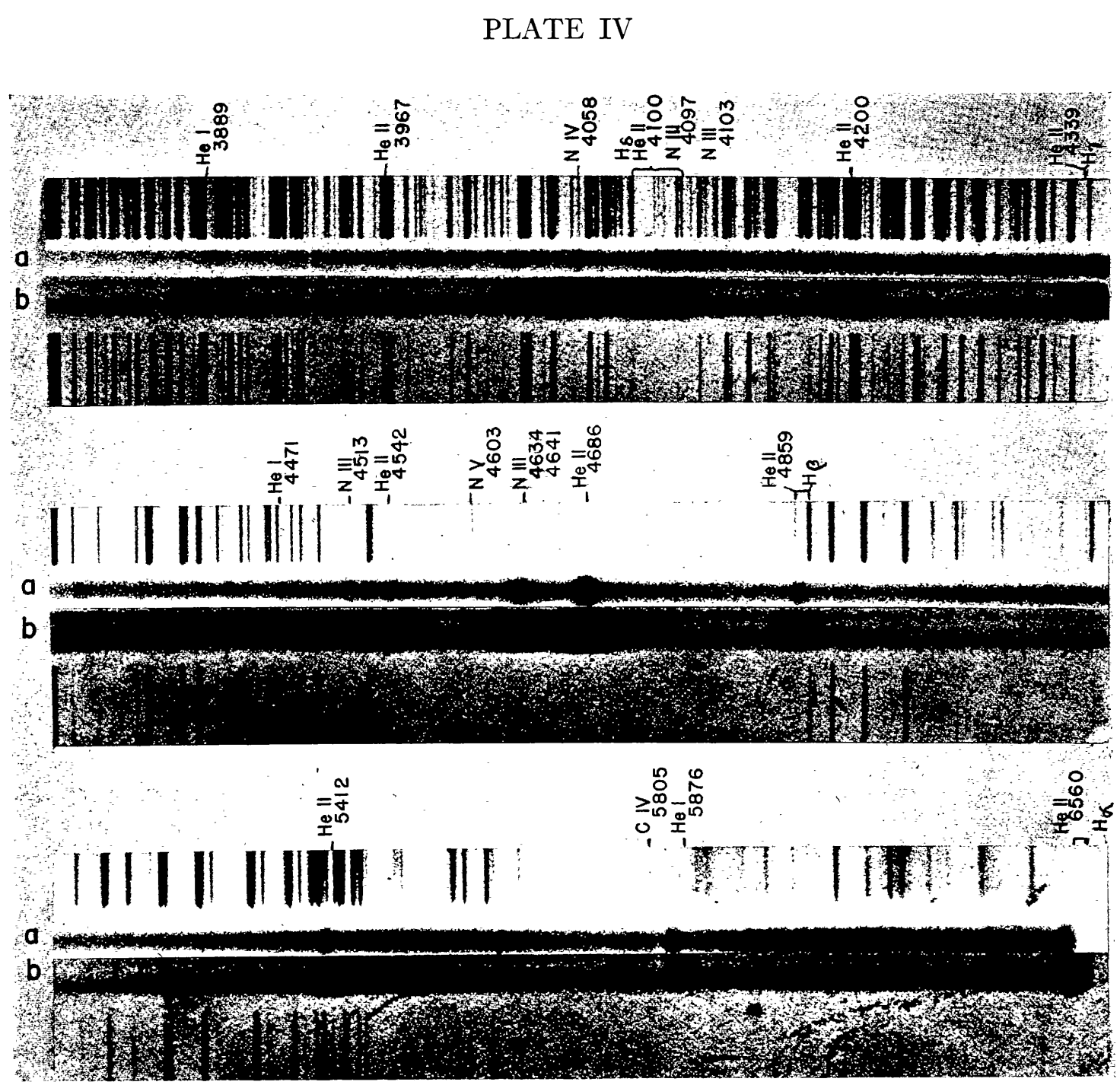

Spectra of two Wolf-Rayet stars belonging to the nitrogen sequence: (a) HD r51932 (WN6+); (b) $\mathrm{HD}$ I92 I63 (WN6). 
PLATE V

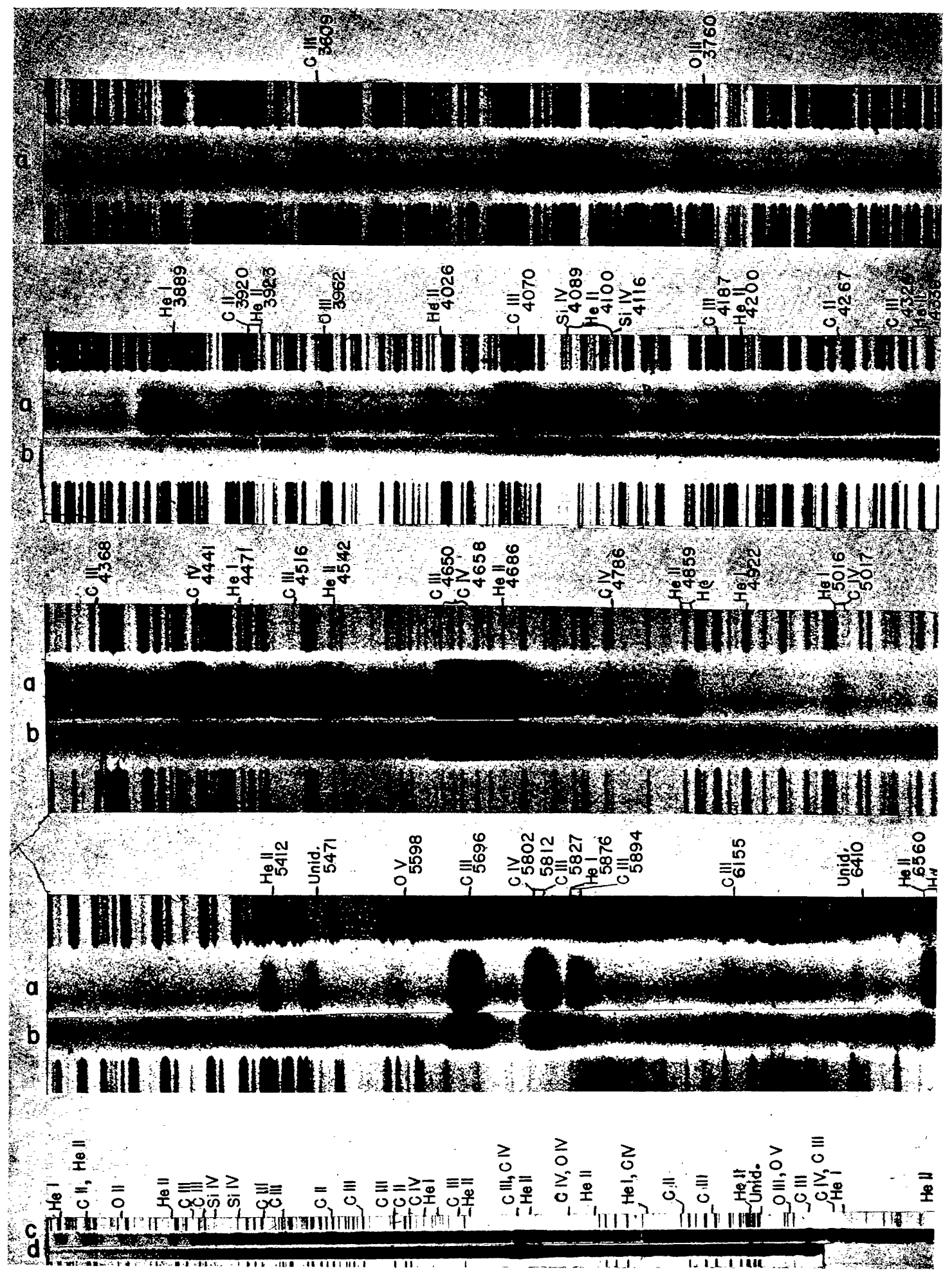

Spectra of Wolf-Rayet stars belonging to the carbon sequence: (a) HD I92103 (WC7); (b) HD $\mathrm{r}_{52270}\left(\mathrm{WC} 6+\right.$ ) (central reversal in $H \beta$ ); (c) $\mathrm{HD}$ I64270 (WC8); (d) $\mathrm{HD} \mathrm{I}_{5} 6385$ (WC6). 


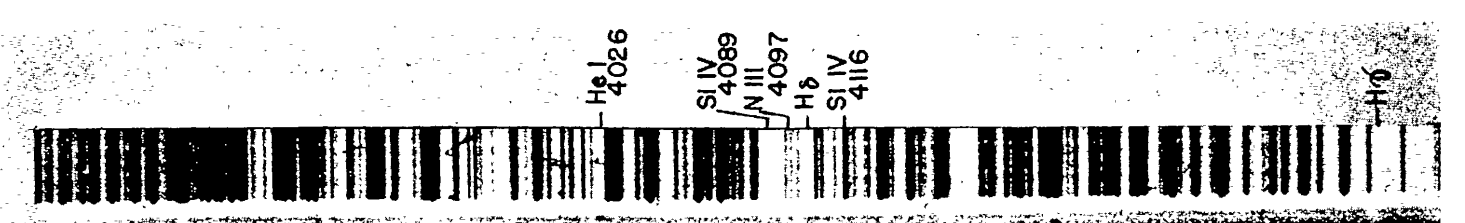

a b 0 a

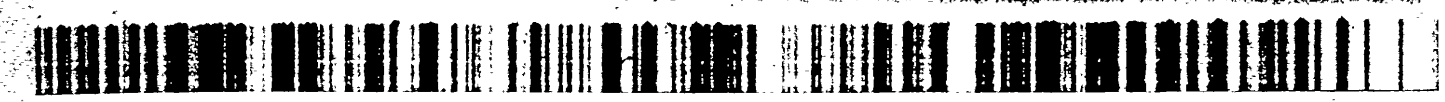
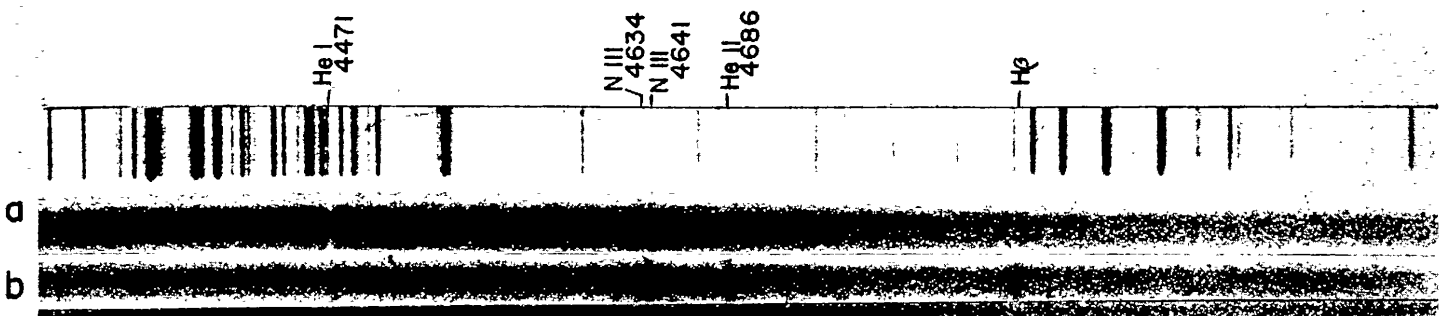

C

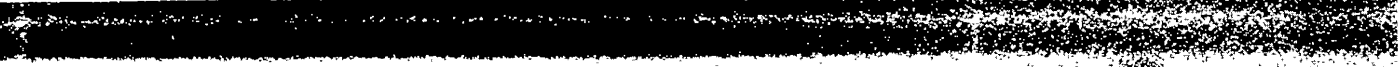

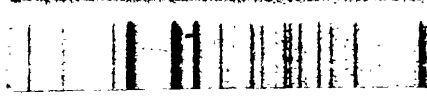

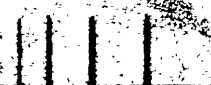

\|\|\|\|\|\|$\|$

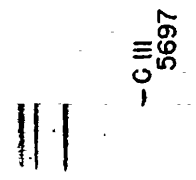

$\stackrel{m}{i}$

b

c

$7 x$ on 30 or

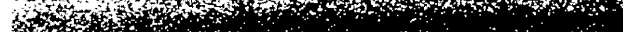

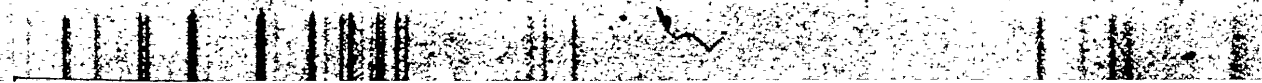

Spectra of three $\mathrm{O}_{7} \mathrm{f}$ stars: (a) HD I5 1804; (b) HD I52408; (c) HD I926639 $_{5}$ 


\section{PLATE VII}

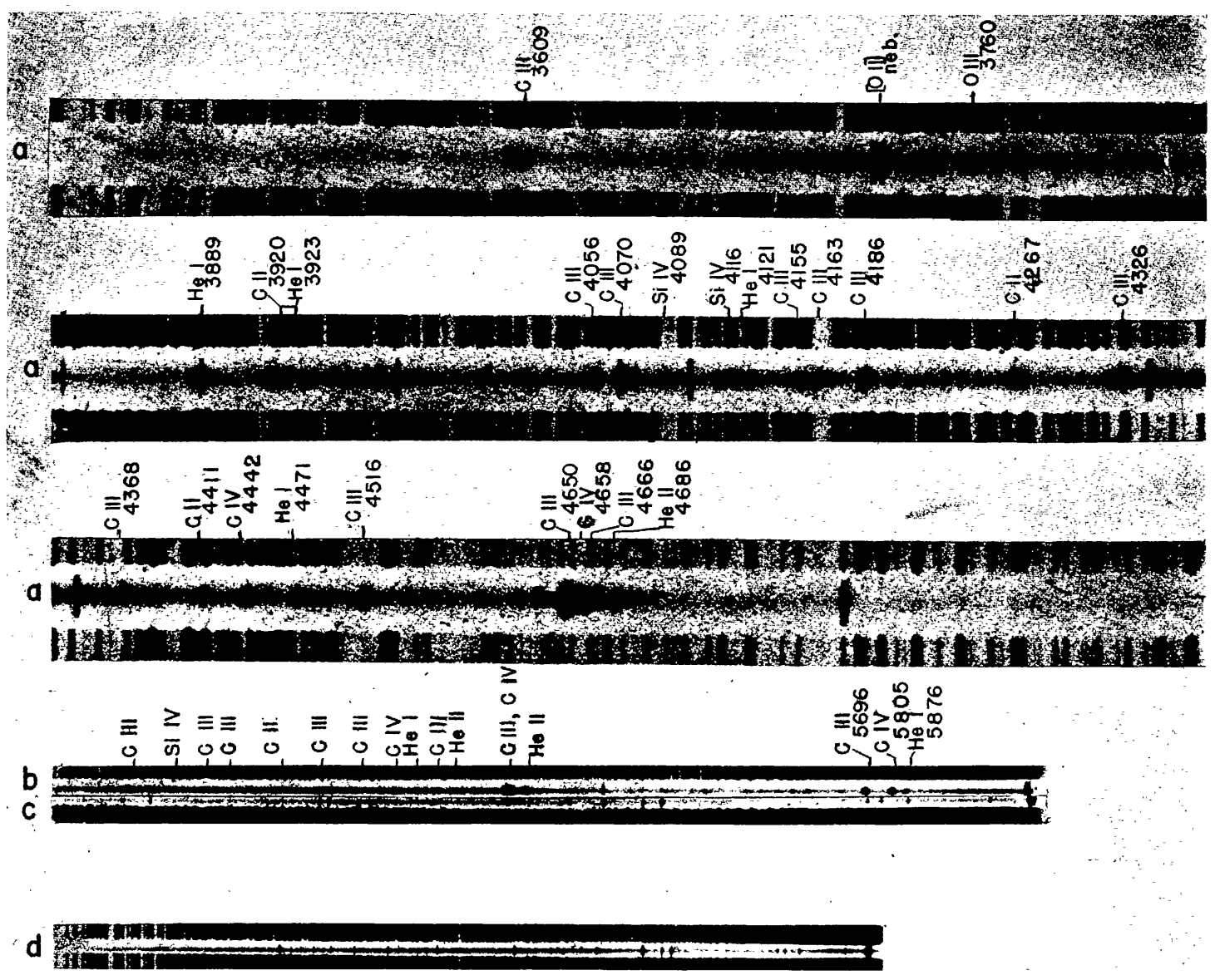

Spectra of planetary nebulae and their nuclei: (a) $\mathrm{BD}+30^{\circ} 3639 ;(b) \mathrm{NGC} 40 ;(c) \mathrm{HD}$ I67362 $(\lambda>$ 4000); (d) $\mathrm{HD}$ I67362 (including ultraviolet region). 